\title{
DIAGNÓSTICO POR IMAGEM NO TRAUMA ABDOMINAL
}

\author{
IMAGING IN ABDOMINAL TRAUMA
}

Fabiano R. Lucchesi ${ }^{1}$; Claudio B. Laguna ${ }^{1}$; Carlos R. Monteiro²; Cecília H. M. A. Prado² \& Jorge Elias Jr³

\begin{abstract}
${ }^{1}$ Médicos Residentes do Hospital das Clínicas da Faculdade de Medicina de Ribeirão Preto da Universidade de São Paulo. ${ }^{2}$ Médicos Assistentes do Serviço de Radiologia do Hospital das Clínicas de Ribeirão Preto. ${ }^{3}$ Docente do Centro de Ciências das Imagens e Física Médica do Hospital das Clínicas da Faculdade de Medicina de Ribeirão Preto da Universidade de São Paulo.

CorResPondênCIA: Prof. Dr Jorge Elias Júnior - Av. Bandeirantes, 3900 - HCFMRP-USP - Campus Universitário, CEP: $14048-900$ Ribeirão Preto - São Paulo. E-mail: jejunior@fmrp.usp.br
\end{abstract}

LUCCHESIFR; LAGUNA CB; MONTEIRO CR; PRADO CHMA \& ELIAS JrJ. Diagnóstico por imagem no trauma abdominal. Medicina, Ribeirão Preto, 32: 401-418, out./dez. 1999.

RESUMO: A presente revisão objetiva descrever os recentes avanços tecnológicos dos métodos de diagnóstico por imagem e sua atual aplicabilidade no manuseio dos pacientes com trauma abdominal, bem como as principais apresentações pelos métodos de imagem dos diversos órgãos envolvidos.

UNITERMOS: Traumatismos Abdominais. Diagnóstico por Imagem. Radiologia.

\section{INTRODUÇÃO}

Verifica-se, nos últimos anos, um aumento na incidência dos casos de trauma, nos serviços de emergências hospitalares, o que motiva a racionalização e hierarquização do atendimento ao politraumatizado, com formação de equipes especificamente treinadas para a assistência no local do trauma (atendimento pré-hospitalar) bem como nos hospitais de referência, que apresentam ambientes físicos adequadamente projetados e equipados para a otimização do atendimento, numa tentativa de promover significativa redução da morbidade e mortalidade ligadas ao trauma. Nas últimas décadas, os métodos de diagnóstico por imagem tornaram-se um recurso indispensável no atendimento inicial, complementando o exame clínico, e, também, no seguimento evolutivo dos pacientes politraumatizados. Abordaremos, resumidamente, as principais indicações e as contra-indicações dos exames de imagem nos traumas abdominais e suas apresentações radiológicas mais comuns.

\section{PRINCÍPIOS GERAIS}

Os ferimentos por arma de fogo resultam em lesão intraperitonial em cerca de $96 \%$, e atingem, principalmente, o fígado, o intestino delgado e o estômago, enquanto o trauma fechado acomete, predominantemente, o baço, o fígado e o retroperitônio ${ }^{(1)}$.

Tradicionalmente, a avaliação do abdome, no politraumatizado, tem sido feita através do exame físico que, quando indicado, é complementado pelo lavado peritonial. A técnica do lavado peritonial é simples, com baixa taxa de complicações, custo reduzido, podendo ser realizada em qualquer hospital. Apesar de serem descritas sensibilidade e especificidade acima de $96 \%$ para o lavado peritonial, as desvantagens da técnica incluem a baixa especificidade para o sítio do sangramento e a impossibilidade de detecção de lesões diafragmáticas ou retroperitoniais ${ }^{(1 / 4)}$.

A radiografia simples tem uma indicação limitada nos casos de trauma abdominal, podendo, porém, ser útil na localização de corpos estranhos, como 
projétil de arma de fogo, e na determinação de fraturas. Eventualmente, na dependência de indicação clínica, pode-se realizar urografia excretora simplificada, também conhecida como "one shot", no intuito de determinar lesões renais antes do encaminhamento do paciente ao centro cirúrgico ${ }^{(5)}$.

A ultra-sonografia vem, de maneira crescente, fazendo parte do algoritmo de atendimento dos pacientes politraumatizados devido a sua rapidez, ao seu caráter portátil e não invasivo, podendo ser repetido sempre que necessário. Pode, também, ser utilizado para monitorar a evolução dos pacientes hemodinamicamente estáveis. Porém, trata-se de uma técnica dependente de operador, limitada pelo tecido subcutâneo excessivo, gás no tubo digestivo e enfisema subcutâneo, aspectos que dificultam a transmissão do feixe sonoro ${ }^{(4)}$. A sensibilidade do ultra-som varia, na literatura, entre 69 a $99 \%$, enquanto a especificidade, entre 86 e $100 \%{ }^{(6)}$. A sensibilidade isolada para o diagnóstico de hemoperitônio é descrita tão alta quanto 91 e $94 \%{ }^{(4,7)}$. Yoshii et al. ${ }^{(8)}$, em trabalho compreendendo 1.239 pacientes avaliados num período de 15 anos, relatam sensibilidade de $94,6 \%$, especificidade de $95,1 \%$, com sensibilidade para o fígado de $92,4 \%$, baço de $90 \%$, rins de $92,2 \%$, pâncreas de $71,4 \%$ e intestino de $34,7 \%$.

A tomografia computadorizada possui a vantagem de poder avaliar as lesões de órgãos parenquimatosos, tanto intra quanto retroperitoniais, bem como a presença e quantificação de líquido livre na cavidade abdominal, de lesões ósseas e de partes moles, porém envolve a remoção do paciente até o departamento de radiologia, uso de contraste iodado, custo mais elevado, necessidade de estabilidade hemodinâmica e cooperação do paciente para o adequado posicionamento durante a realização do exame, apresentando dificuldade relativa em detectar lesões do trato gastrintestinal. A sensibilidade e especificidade descritas na literatura, para tomografia computadorizada, situam-se acima dos $97 \%^{(1,2,4)}$.

O protocolo da tomografia computadorizada convencional compreende cortes axiais com espessura de $10 \mathrm{~mm}$ e incremento de $10 \mathrm{~mm}$, abrangendo-se abdome e pelve, para que não seja subestimada a presença de possível hemoperitônio, e exige a utilização de contraste iodado endovenoso, oral e, eventualmente, por via retal. O uso do contraste endovenoso é obrigatório nos casos de trauma, exceto se houver contraindicações, como alergia ou insuficiência renal e, para tanto, infundem-se, inicialmente, $50 \mathrm{ml}$ de contraste iodado a $60 \%$ com velocidade de infusão de $2-3 \mathrm{ml} / \mathrm{s} \mathrm{e}$ o restante a $1 \mathrm{ml} / \mathrm{s}$. Em crianças, a dose utilizada de contraste é de $2 \mathrm{ml} / \mathrm{kg}$ de peso. O contraste oral iodado 1 a $2 \%$, num volume de $500 \mathrm{ml}$, deve ser iniciado 30 minutos antes do exame e $250 \mathrm{ml}$ imediatamente do início do exame, preferencialmente gelado. Quando em função da gravidade clínica do paciente não se puder administrar previamente o contraste, deve-se oferecer 120 a $180 \mathrm{ml}$ imediatamente antes de se iniciar o exame para contrastação do estômago e duodeno. $\mathrm{O}$ contraste iodado, numa concentração de 2 a $3 \%$, por via retal, é infundido imediatamente antes do início do exame, num volume de $150 \mathrm{ml}$, no intuito de melhor delineamento do intestino grosso ${ }^{(1,9,10,11)}$. Kelly et al. recomendam a realização da fase não contrastada para a identificação de hematomas hepáticos hiperdensos, que se tornam isodensos na fase con$\operatorname{trastada}^{(12)}$.

É imprescindível a utilização de janelas para partes moles (largura de janela estreita) e pulmonar (largura de janela ampla), para que seja possível a detecção de lesões parenquimatosas, de líquido livre e de pneumoperitônio. A arteriografia teve a sua indicação reduzida em função do surgimento dos demais métodos diagnósticos menos invasivos ${ }^{(2)}$.

\section{HEMOPERITÔNIO}

Em função dos recessos anatômicos e da ação da gravidade, o líquido livre intraperitonial acumulase, preferencialmente, na pelve, no espaço de Morison (espaço compreendido entre o fígado e o rim direito, que se comunica, cranialmente, com o espaço periepático e, caudalmente, com a goteira parietcólica direita) (Figura 1), topografia periepática e periesplênica (Figura 2) e ao longo das goteiras parietcólicas, mais à direita. Assim, é obrigatório que os cortes tomográficos alcancem a pelve nos casos de trauma, e que o espaço de Morison seja atentamente avaliado, pois, em $97 \%$ dos casos de laceração hepática ou esplênica, ocorrerá acúmulo de líquido nesta região ${ }^{(13)}$. O tipo de líquido coletado poderá ser composto, isoladamente, por sangue, bile, urina, conteúdo da alça intestinal lesada, líquido de lavado peritonial ou, ainda, associação dos mesmos.

O ultra-som claramente demonstra o acúmulo de líquido com uma coleção anecóica, localizada, preferencialmente, nos recessos peritoniais supracita$\operatorname{dos}^{(14)}$. 


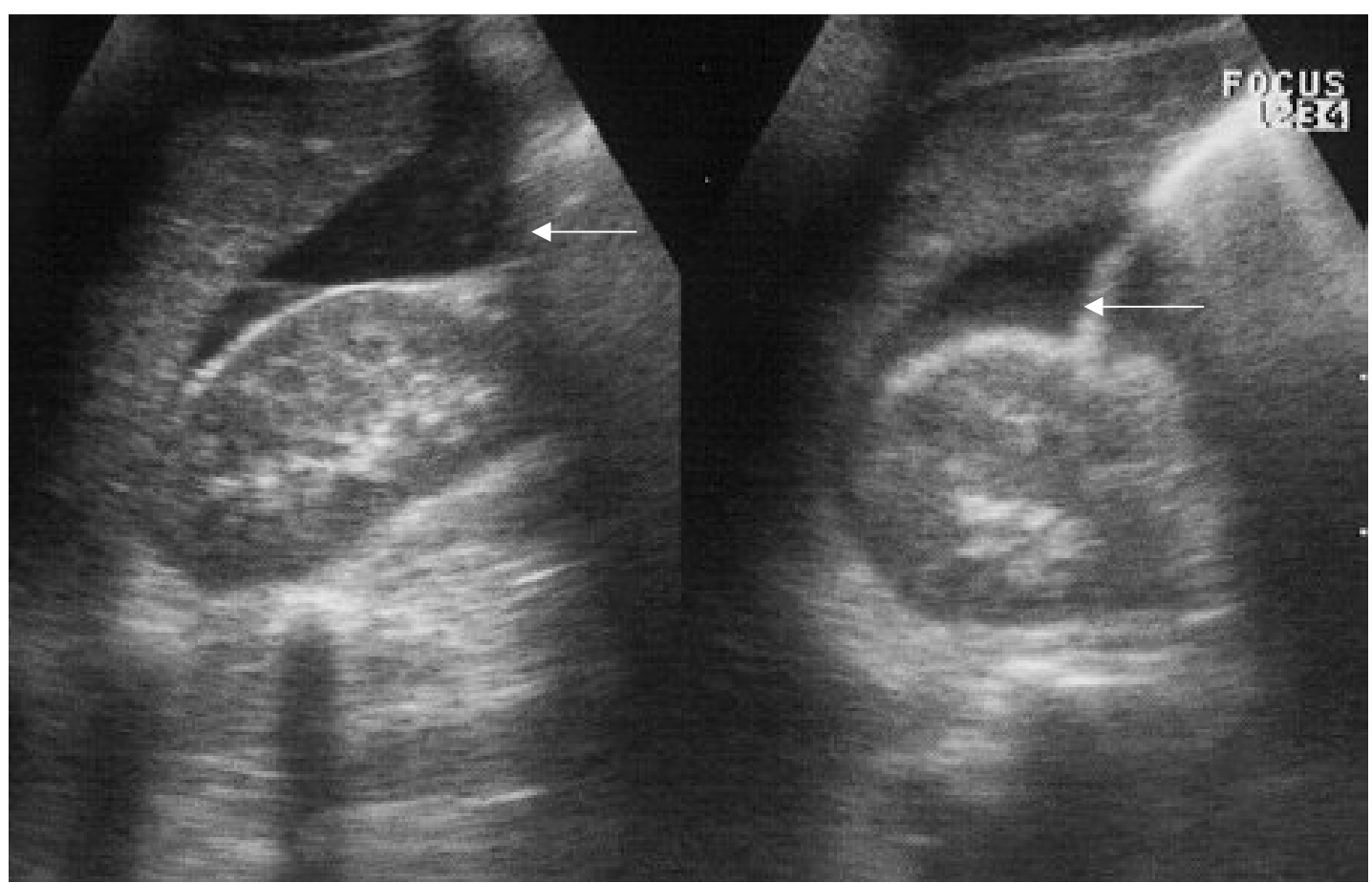

Figura 1 - Ultra-som, mostrando líquido (sangue) coletado no espaço de Morison (seta) em paciente com trauma esplênico, visto como coleção anecóica.

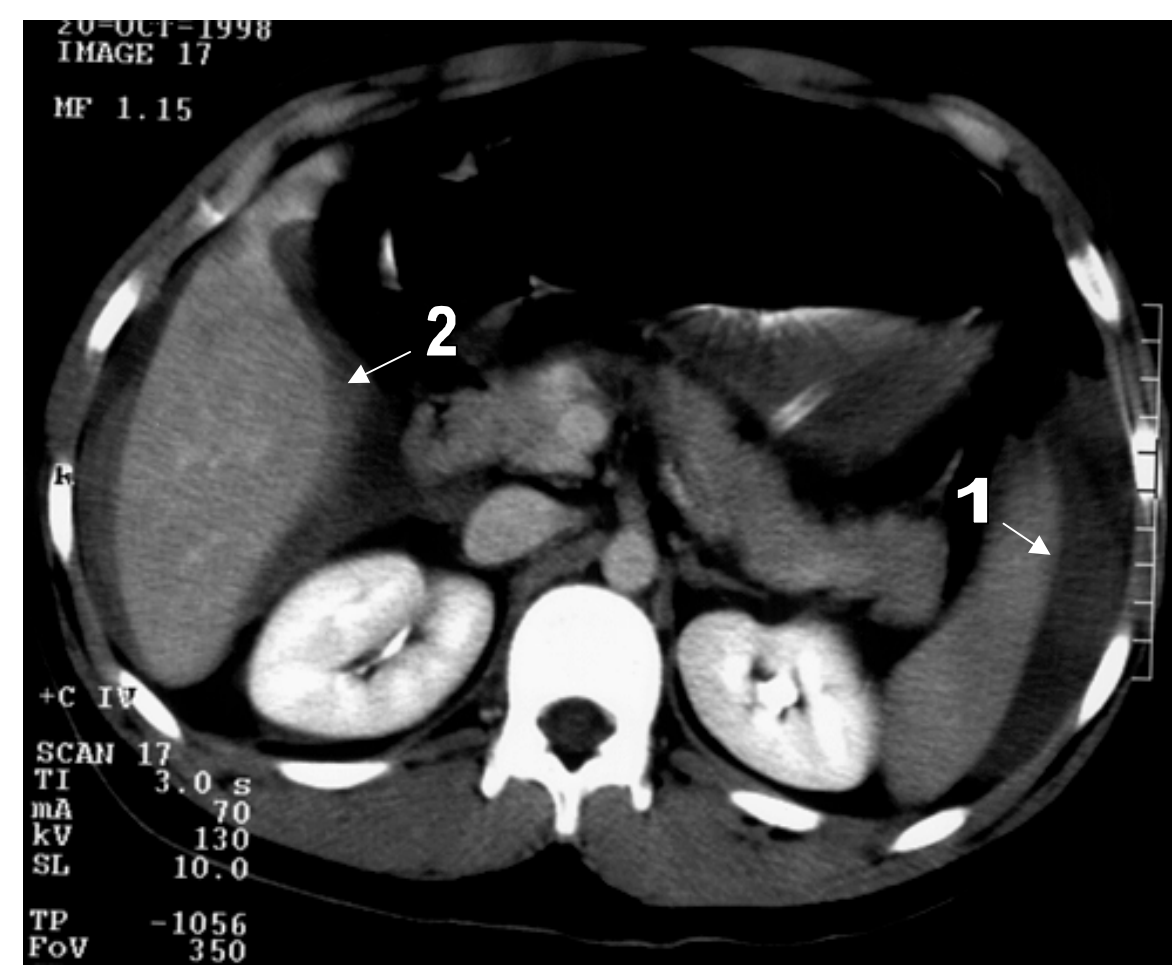

Figura 2 - Tomografia computadorizada, apresentando líquido periesplênico (1) e periepático (2) em paciente com trauma hepático (não mostrado no corte tomográfico). 
O aspecto do hemoperitônio, na tomografia computadorizada, dependerá do momento em que o exame é realizado, pois o coeficiente de atenuação do sangue sofre alterações conforme os estágios de degradação da hemoglobina. O sangue fresco extravasado apresenta coeficiente de atenuação entre 35 e 45 unidades Hounsfield (UH), próximo ao sangue circulante, porém menor que os tecidos abdominais realçados, após utilização de contraste endovenoso iodado, aparecendo, portanto, hipodenso.O sangue coagulado em função da retração do coágulo e da separação do plasma, apresenta um coeficiente de atenuação mais elevado em torno de 60 a $80 \mathrm{UH}$, eventualmente chegando até $100 \mathrm{UH}$, tornando-se portanto mais denso. Com a lise do coágulo, acelerada pelos movimentos respiratórios e pelo peristaltismo intestinal, ocorre uma redução no conteúdo protéico, com resultante diminuição do coeficiente de atenuação, tornando-se o líquido cada vez mais hipodenso, até aproximar-se do valor da água ${ }^{(1)}$. De acordo com Federle \& Jeffrey Jr, o hemoperitônio com menos de 48 horas sempre apresenta coeficiente de atenuação acima de $30 \mathrm{UH}^{(9,13)}$. O coeficiente de atenuação é afetado por uma série de outros fatores além dos descritos anteriormente e um exemplo é o nível do hematócrito no paciente anêmico, onde o coeficiente será, conseqüentemente, menor, e outro exemplo é a largura da janela utilizada para visibilização da imagem, uma vez que as janelas utilizadas para partes moles abdominais (entre 250 e $500 \mathrm{UH}$ ) não são tão estreitas como as de crânio, promovendo, assim, uma diminuição do contraste entre tecidos de densidades similares.

São descritos dois outros sinais tomográficos no hemoperitônio: sinal do coágulo sentinela ("sentinel clot sign") ${ }^{(11)}$ e o efeito hematócrito $^{(1)}$. O primeiro refere-se à presença de uma área mais densa em um local específico intra-abdominal, podendo corresponder ao sítio de hemorragia inicial (hematoma), sendo útil na identificação do local do sangramento. $\mathrm{O}$ efeito hematócrito decorre da separação do plasma pela retração do coágulo, posicionando-se superiormente ao mesmo.

\section{TRAUMA HEPÁTICO}

O trauma hepático pode resultar em hematomas intraparenquimatosos, subcapsulares, laceração, contusão, lesão vascular ou das vias biliares. O local mais freqüente de lesão é o lobo direito, principalmente nos segmentos posteriores.

O hematoma subcapsular, caracteristicamente, assume um formato semilunar, côncavo-convexo, exercendo efeito de massa sobre o parênquima subjacente, localizado, geralmente, anterolateralmente ao lobo direito (Figura 3). A laceração apresenta-se como imagem hipodensa, linear ou ramificada, acompanhando os vasos portais e na periferia do órgão $\mathrm{O}^{(1,9,10,11)}$ (Figura 4 a 6). Mirvis et al. ${ }^{(15)}$ graduaram a lesão hepática em cinco graus através dos achados tomográficos (Tabela I). Segue, em adendo anexo, a classificação da "Organ Injury Scale" (OIS), que é a mais seguida atualmente, por representar o Colégio Americano de Cirurgiões ${ }^{(16,17)}$. 


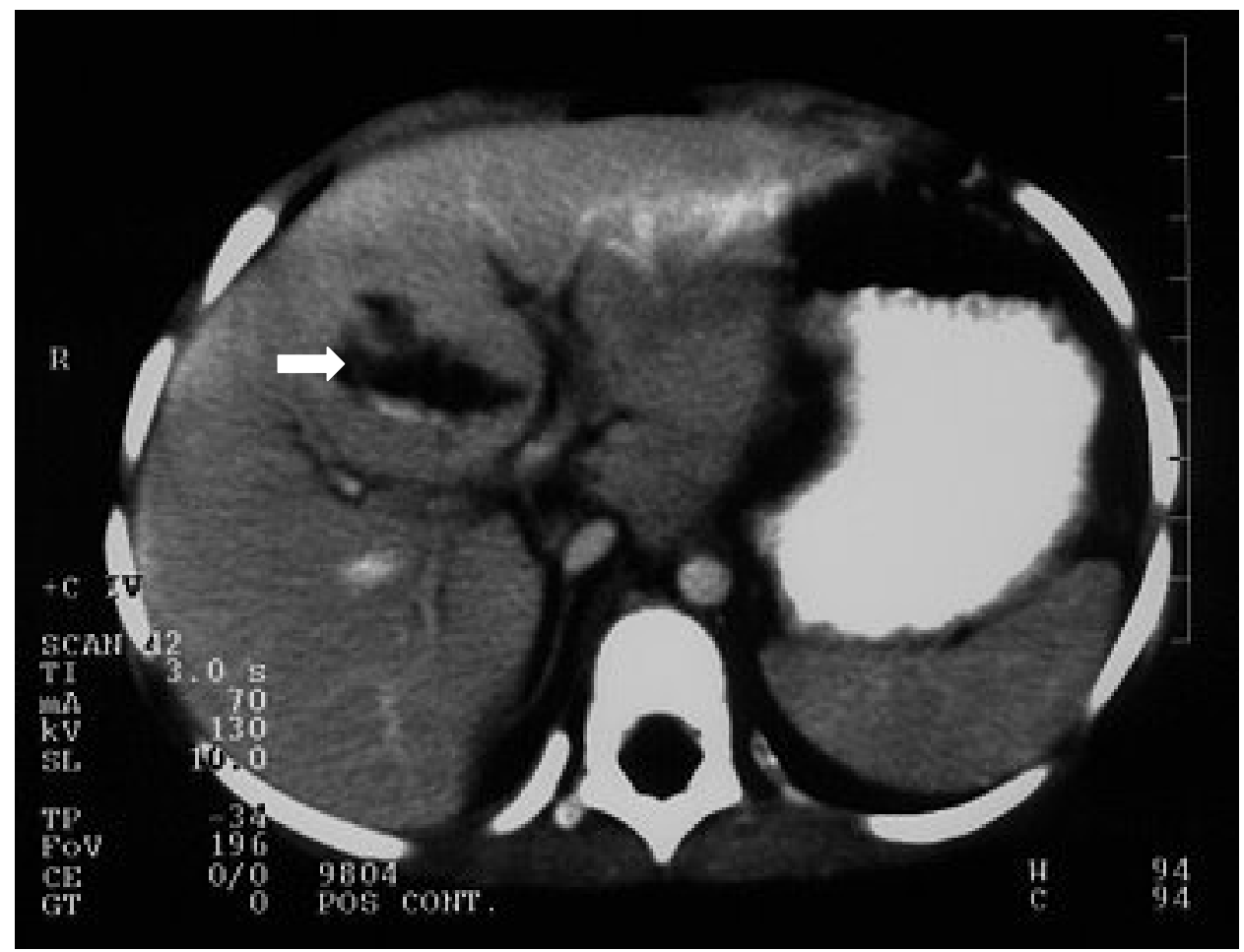

Figura 4 - Tomografia computadorizada, apresentando laceração hepática, vista comohipodensidade.

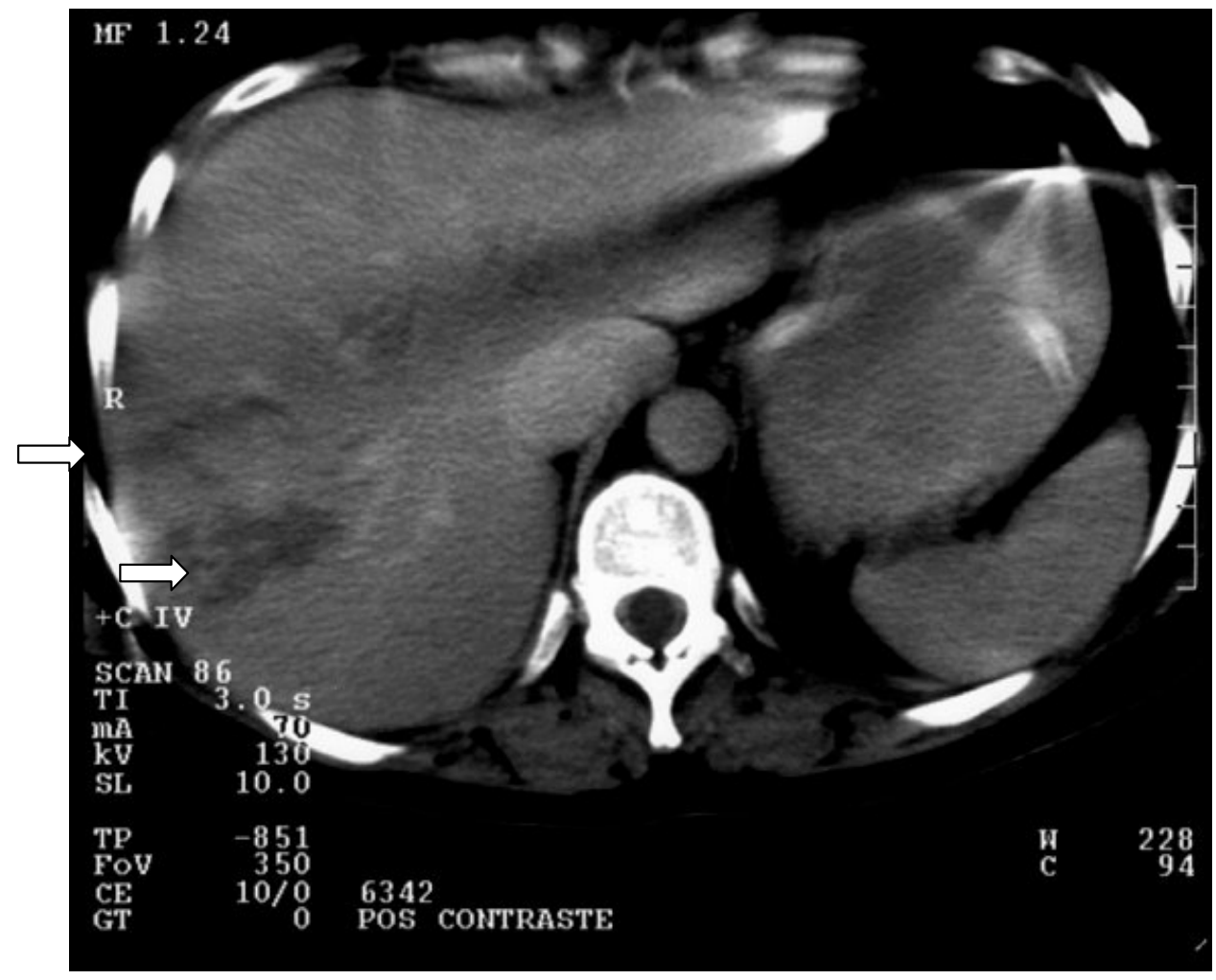

Figura 5 - Lacerações hepáticas superficiais, vistas na tomografia computadorizada. 


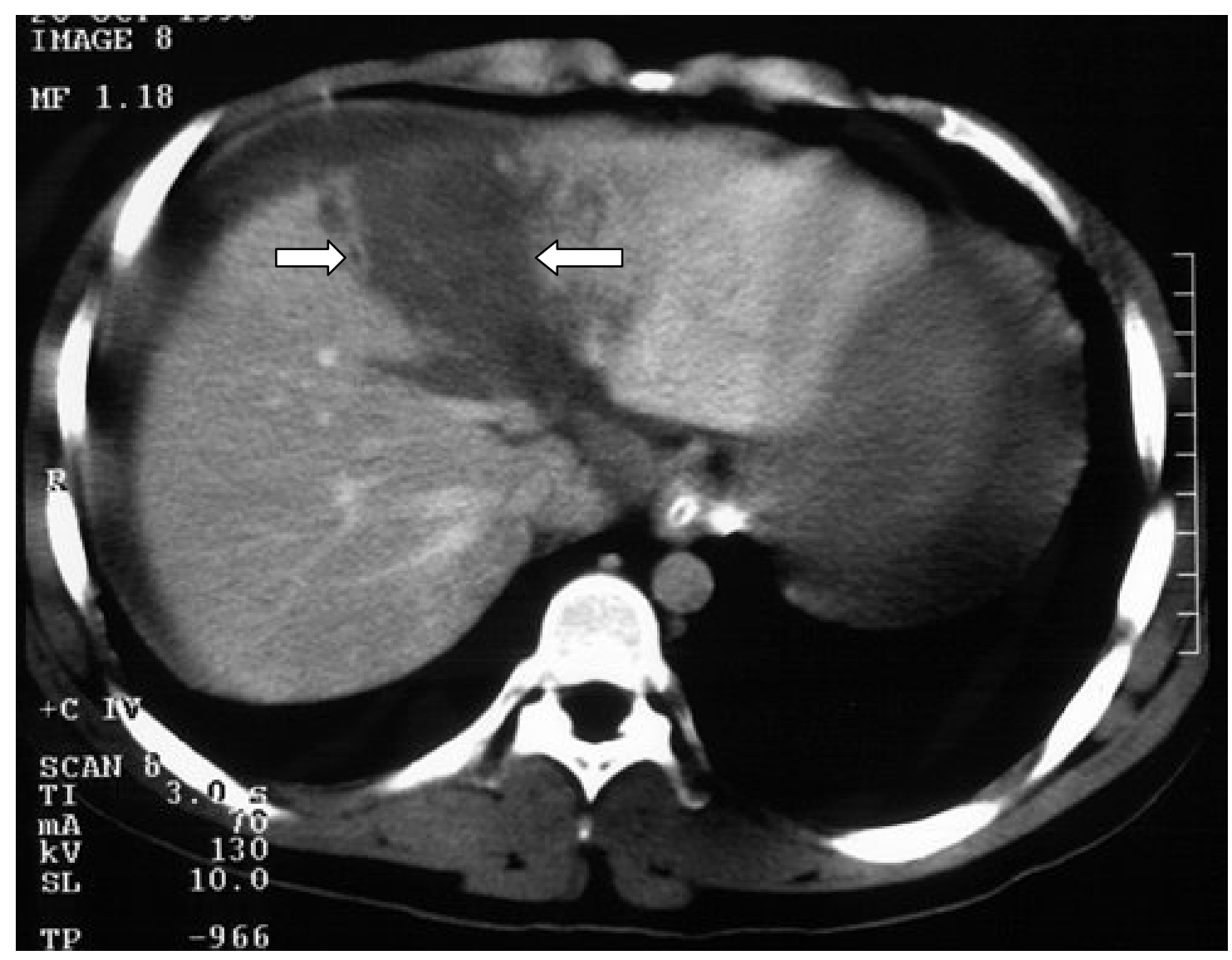

Figura 6 - Extensa lesão hepática com destruição lobar do parênquima, vista na tomografia computadorizada.

\section{Tabela I - Classificação tomográfica do trauma} hepático

- Grau 1 - avulsão capsular, lacerações superficiais $<1 \mathrm{~cm}$ de profundidade, hematoma subcapsular com espessura máxima $<1 \mathrm{~cm}$.

- Grau 2 - Laceração com profundidade entre 1 a $3 \mathrm{~cm}$, hematoma central ou subcapsular com diâmetro entre 1 a $3 \mathrm{~cm}$.

- Grau 3 - Laceração com profundidade $>3 \mathrm{~cm}$, hematoma central ou subcapsular com diâmetro > $3 \mathrm{~cm}$.

- $\quad$ Grau 4 - Hematoma central ou subcapsular com diâmetro $>10 \mathrm{~cm}$, destruição lobar do parênquima (maceração) ou desvascularização.

- Grau 5 - Destruição bilobar do parênquima ou desvascularização.
A tomografia também pode ser útil no seguimento da resolução das lesões decorrentes do trauma hepático. Deve ser ressaltado que, durante a resolução do hematoma, a área lesada pode parecer mais hipodensa, com maiores dimensões em função de efeito osmótico e de limites mais regulares. As principais causas de erros diagnósticos na tomografia computadorizada estão listados na Tabela II.

Tabela II - Causas de erros diagnósticos no trauma hepático, na tomografia computadorizada

\begin{tabular}{|ll|}
\hline \multicolumn{1}{|c|}{ Falso Negativo } & \multicolumn{1}{c|}{ Falso Positivo } \\
\hline $\begin{array}{l}\text { Trauma em fígado } \\
\text { com esteatose }\end{array}$ & $\begin{array}{l}\text { Nível aéreo dentro do } \\
\text { estômago ou presença de } \\
\text { sonda nasogástrica, } \\
\text { promovendo artefato. } \\
\\
\end{array}$ \\
& $\begin{array}{l}\text { Artefato de "endurecimento" } \\
\text { do feixe. }\end{array}$ \\
\hline
\end{tabular}




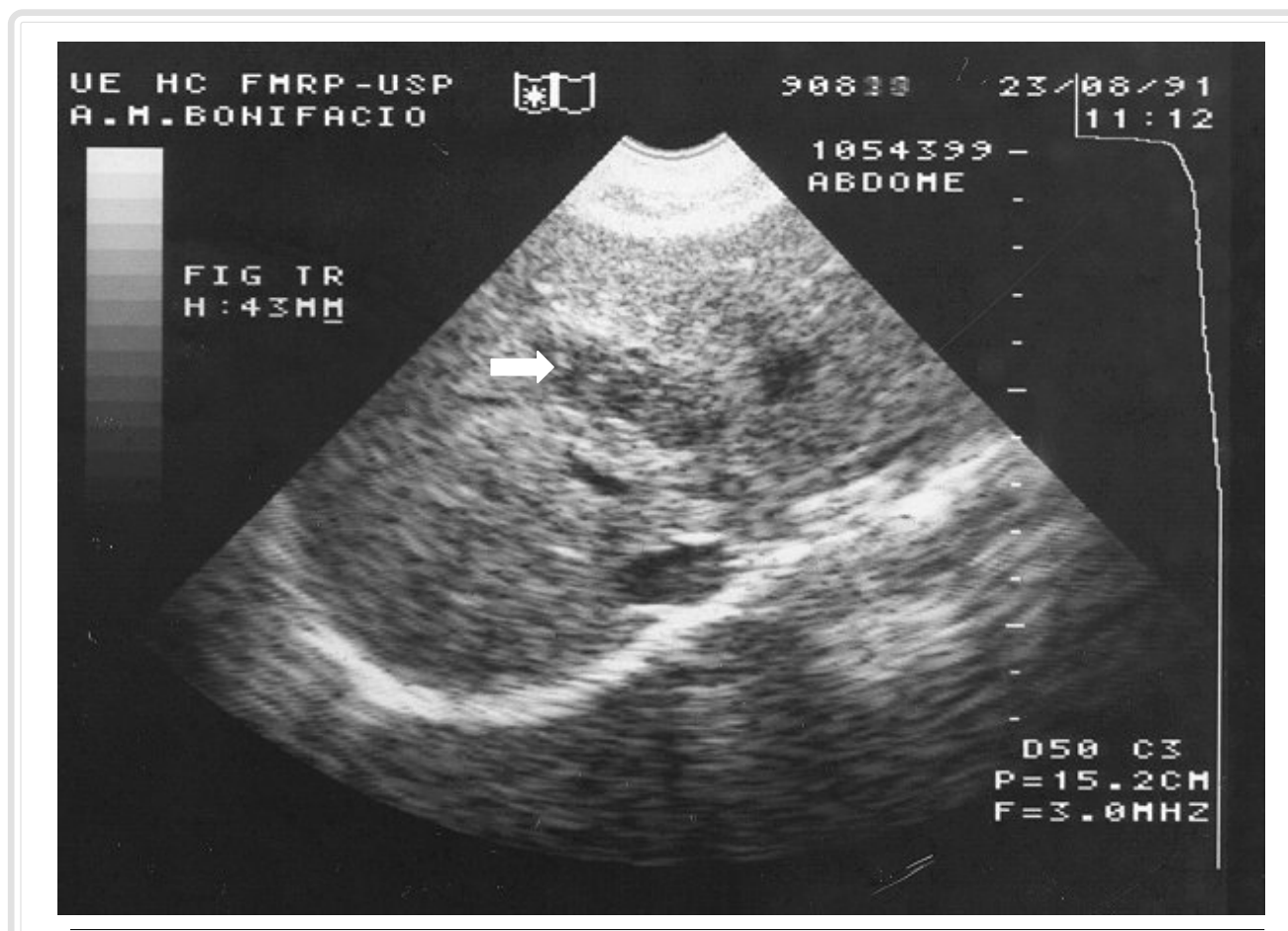

Figura 7 - Laceração hepática, apresentando-se como faixa hipoecóica pelo ultra-som (seta).

Na avaliação ultra-sonográfica, o sangramento agudo aparece ecogênico, tornando-se hipoecóico na primeira semana e resolvendo-se, geralmente, em cerca de duas a três semanas ${ }^{(14,18,19)}$ (Figura 7).

\section{TRAUMA ESPLÊNICO}

Atualmente, as equipes cirúrgicas vem, progressivamente, adotando uma conduta mais conservadora, na tentativa de preservação do parênquima esplênico, uma vez que há uma maior chance de infecção naqueles pacientes esplenectomizados. Entretanto , não há uma boa correlação entre os achados dos métodos de imagem e prognóstico do manuseio conservador do paciente, necessitando a terapêutica ser estabelecida com base em critérios clínicos, hemodinâmicos, em associação com os achados dos métodos de imagem. As principais causas de diagnóstico errôneos são listadas na Tabela III.

No exame de ultra-som realizado na sala de urgência, o sangue apresenta-se hiper ou hipoecóico, identificando-se o parênquima esplênico com ecotextura heterogênea (Figuras 8 e 9 b). É possível que o sangue se apresente isoecogênico em relação ao parênquima adjacente, dificultando o diagnóstico, dando a impressão de uma esplenomegalia. O sangue, quando coletado em topografia subcapsular, tem uma forma côncava - convexa, (Figura 9a) enquanto o de localização pericapsular apresenta um contorno irregular (Figura 10); eventualmente, a individualização da cápsula esplênica ajuda na localização do sangramento $^{(14,20)}$.

Mirvis et al. ${ }^{(21)}$ também graduaram a injúria esplênica em quatro graus através dos achados tomográficos (Tabela IV). Na fase não contrastada da tomografia computadorizada, o hematoma intraesplênico é visibilizado como área isodensa ou discretamente hiperdensa em relação ao parênquima esplênico e hipodensa na fase contrastada (Figuras 11 e 12). Na contusão, a área hipodensa tem limites mal definidos, enquanto, na laceração, a área focal hipodensa é linear ou ramificada ${ }^{(1,9,10,11)}$.

Tabela III - Causas de erro na análise tomográfica do trauma esplênico

1. Artefato de movimento, simulando hematoma subcapsular.

2. Efeito de volume parcial.

3. Lobulação esplênica, principalmente no lobo superior.

4. Infarto esplênico prévio.

5. Líquido periesplênico devido a ascite ou lavado peritonial.

6. Gordura entre o baço e alças intestinais não contrastadas. 


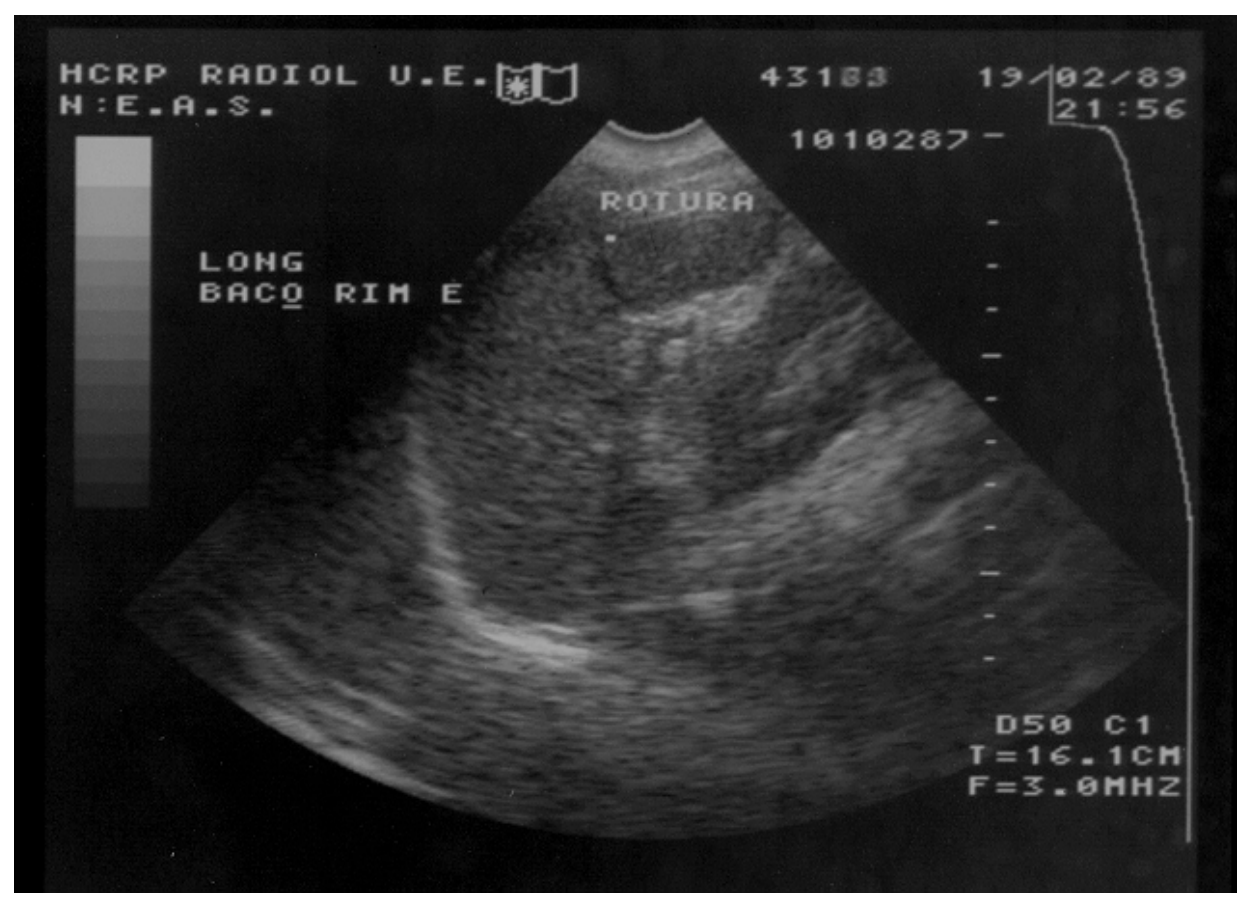

Figura 8 - Rotura esplênica com imagem anecóica central, vista na ultra-sonografia.

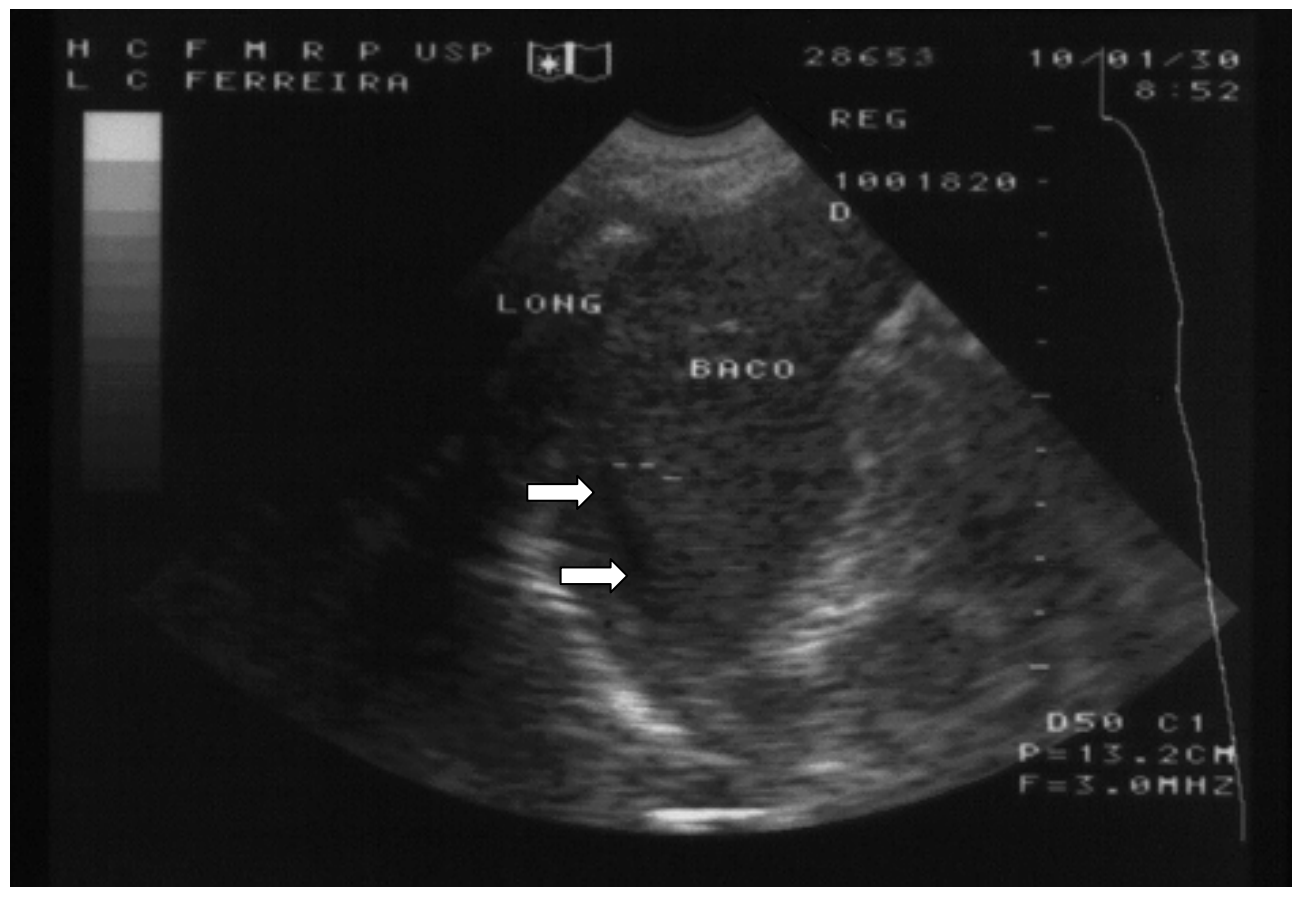

Figura 9 a - Lesão esplênica com hematoma subcapsular (setas), vista no ultra-som. 


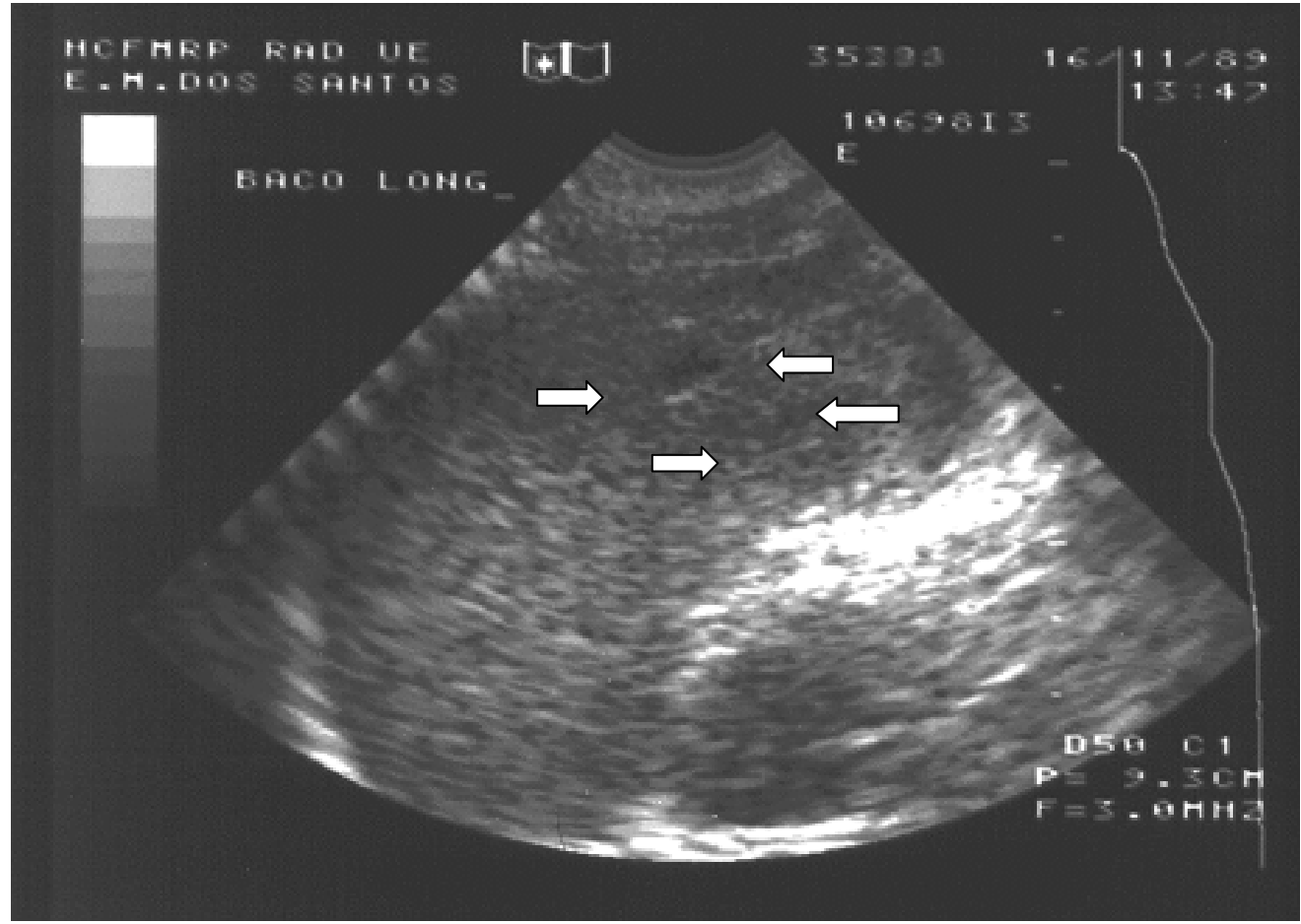

Figura $9 b$ - Lesão esplênica heterogênea, vista no ultra-som, indicando hematoma na fase aguda do trauma.

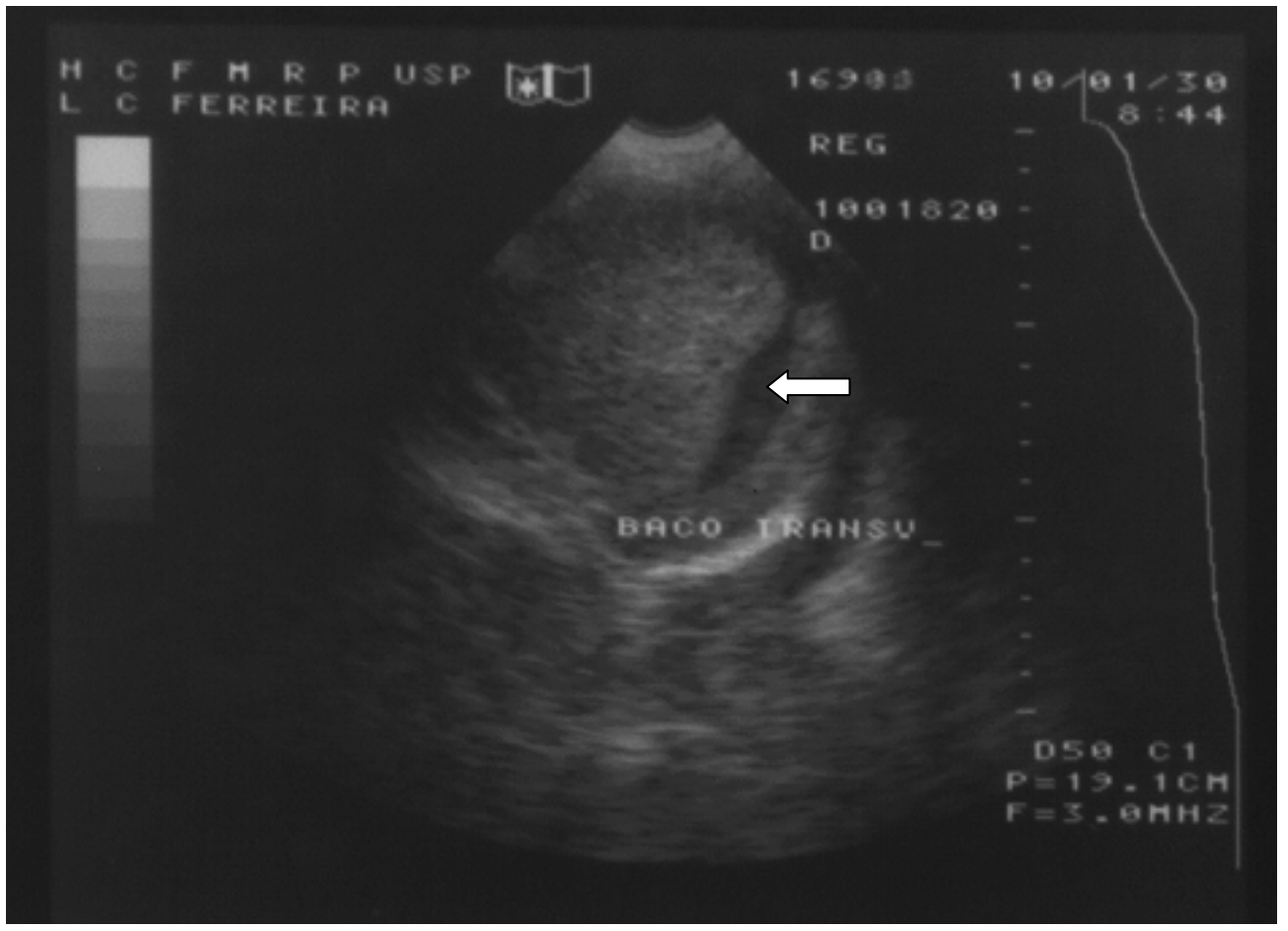

Figura 10 - Lesão esplênica com hematoma periesplênico não restrito pela cápsula (seta), vista no ultra-som. 
Tabela IV - Classificação tomográfica do trauma esplênico

- Grau 1 - avulsão capsular, laceração superficial e hematoma subcapsular com espessura $<1 \mathrm{~cm}$.

- Grau 2 - laceração mais profunda (1 a $3 \mathrm{~cm}$ de profundidade) ou central e hematoma capsular < $3 \mathrm{~cm}$.

- Grau 3 - laceração mais profunda que $3 \mathrm{~cm}$ e central ; hematoma capsular $>3 \mathrm{~cm}$.

- Grau 4 - fragmentação ou desvascularização esplênica.

\section{TRAUMA RENAL}

A avaliação pelo ultra-som é menos vantajosa que pela tomografia devido à localização retroperitonial do órgão, limitando a visibilização dos achados. Os hematomas podem apresentar-se com textura hipo, hiperecóica ou heterogênea, sendo que as coleções perirrenais também devem ser pesquisadas ${ }^{(22)}$.

$\mathrm{Na}$ tomografia computadorizada, a contusão é visibilizada como uma área focal e irregular do parênquima, sem realce na fase contrastada, associada a aumento localizado ou difuso do rim, enquanto, nas fases tardias, podem existir imagens focais hiperdensas dentro do parênquima, representando urina extravasada com contraste concentrado. Já a laceração aparece como área linear, irregular, hipodensa dentro do parênquima renal, havendo extravasamento de urina na presença de comprometimento do sistema coletor. $\mathrm{O}$ hematoma subcapsular apresenta aspecto lentiforme, hipodenso, comprimindo o parênquima subjacente. As imagens de falha de enchimento dentro do sistema coletor podem representar coágulos. O comprometimento dos vasos renais, seja por ruptura ou por trombose, manifesta-se através de rins com dimensões reduzidas e sem efeito nefrográfico (Figuras 13 a 16). Nos casos de avulsão da pelve renal ou ureter, nota-se rim com função conservada associado a grande extravasamento de urina e ausência de contraste no ureter distal ${ }^{(1,9,10,11)}$.

Mirvis, através dos achados tomográficos, classificou o trauma renal em quatro graus ${ }^{(23)}(\mathrm{Ta}-$ bela V).

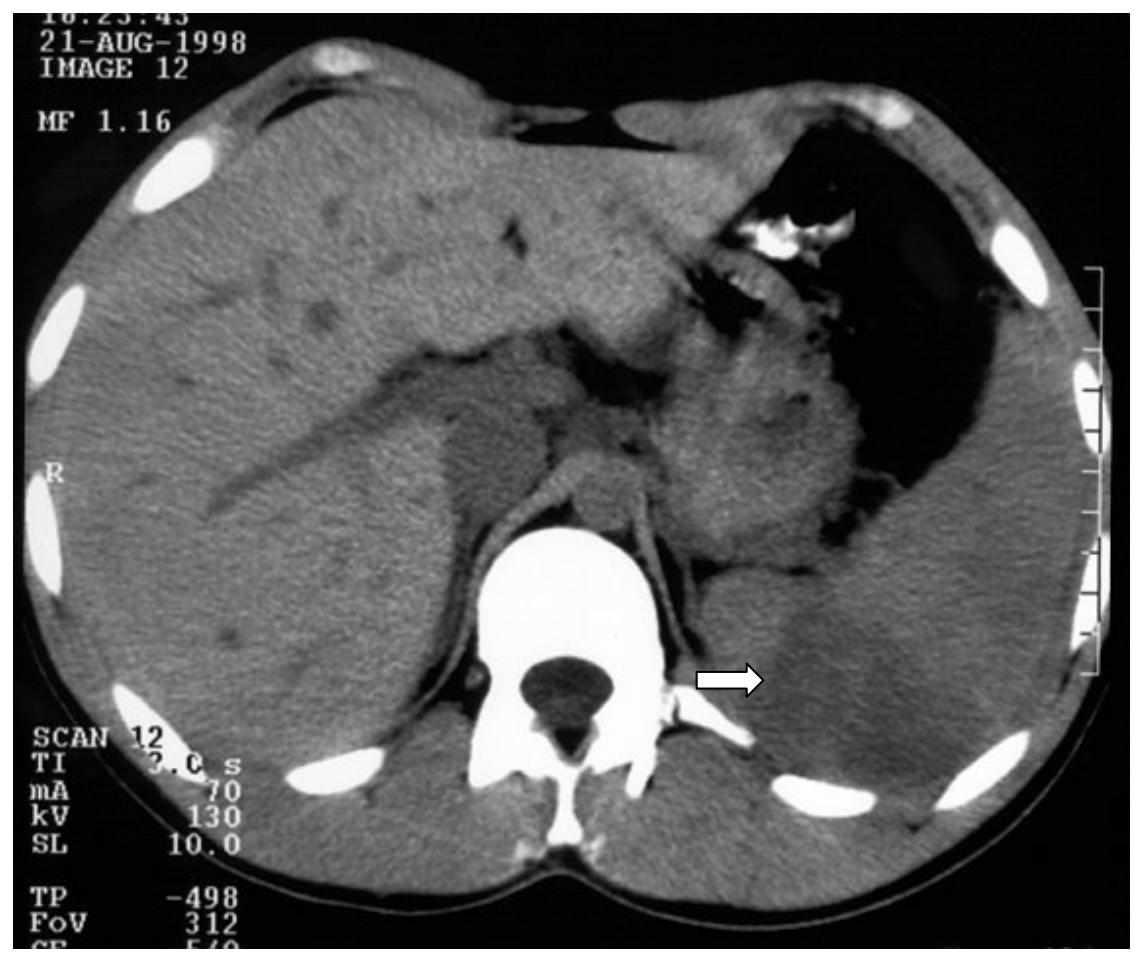

Figura 11 - Lesão esplênica grau III com área central hipodensa extensa (seta), vista na tomografia computadorizada. 


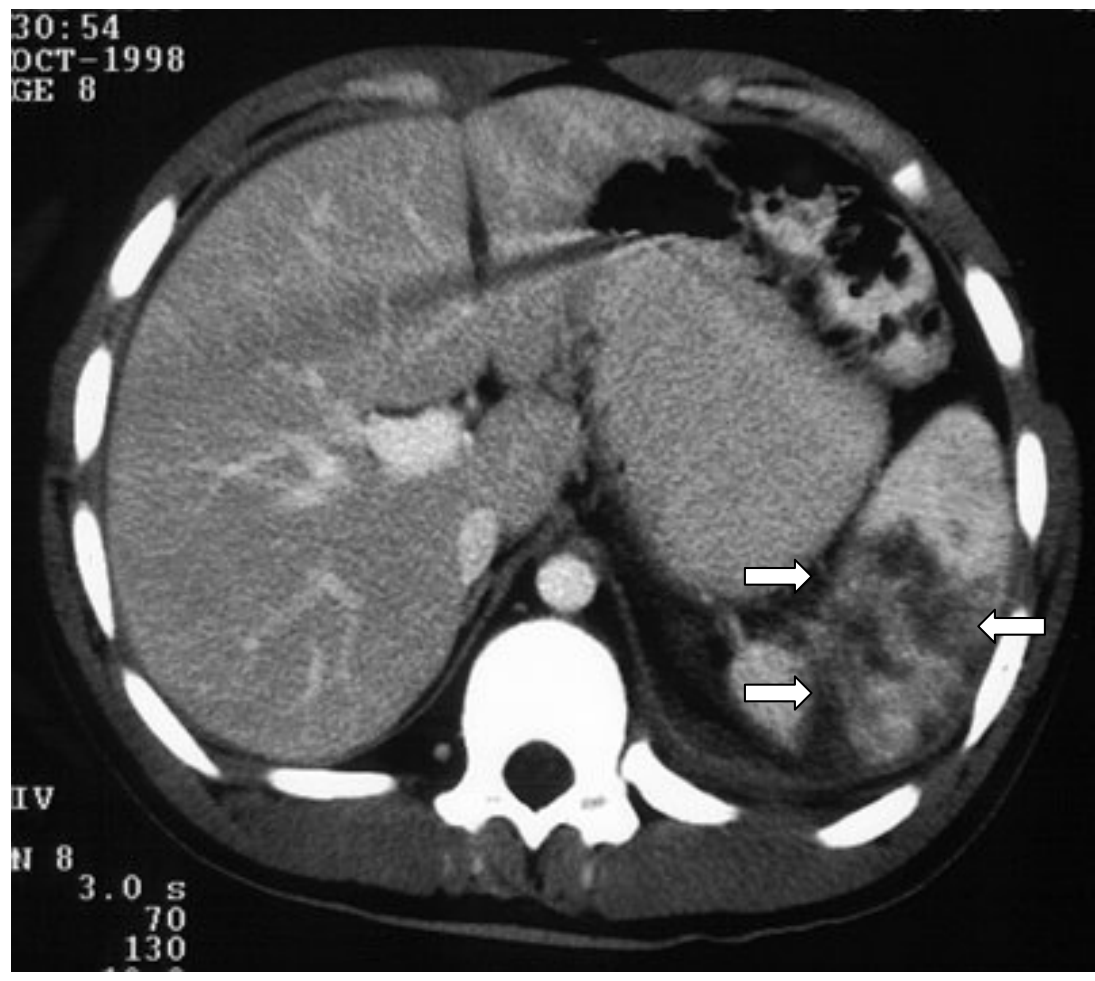

Figura 12- Lesão esplênica difusa com fragmentação, vista na tomografia computadorizada, com contraste endovenoso,

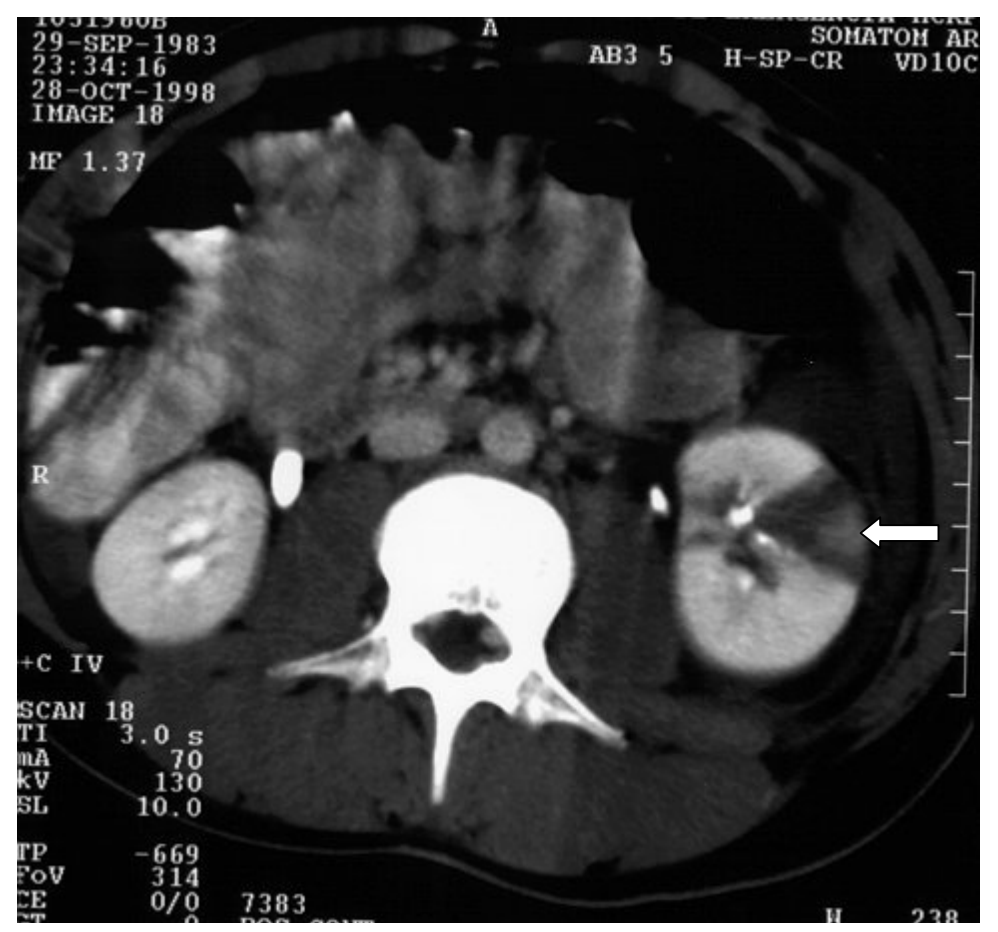

Figura 13 - Captação assimétrica de contraste renal, mostrada pela tomografia computadorizada, com hipodensidade, estendendose até a pelve renal. Lesão renal grau II. 


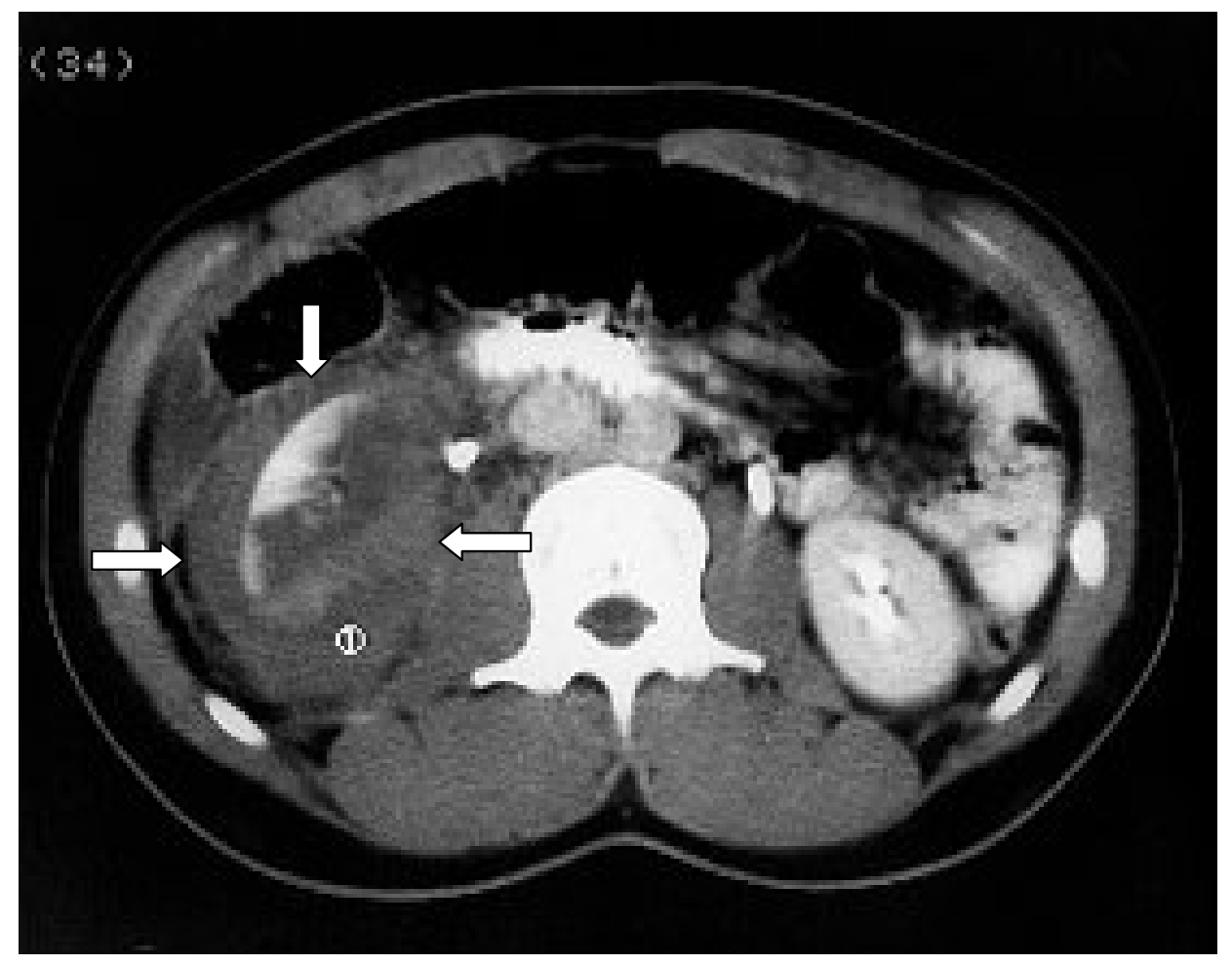

Figura 14 - Laceração renal extensa (setas), com hematoma perirrenal, visualizada através da tomografia computadorizada.

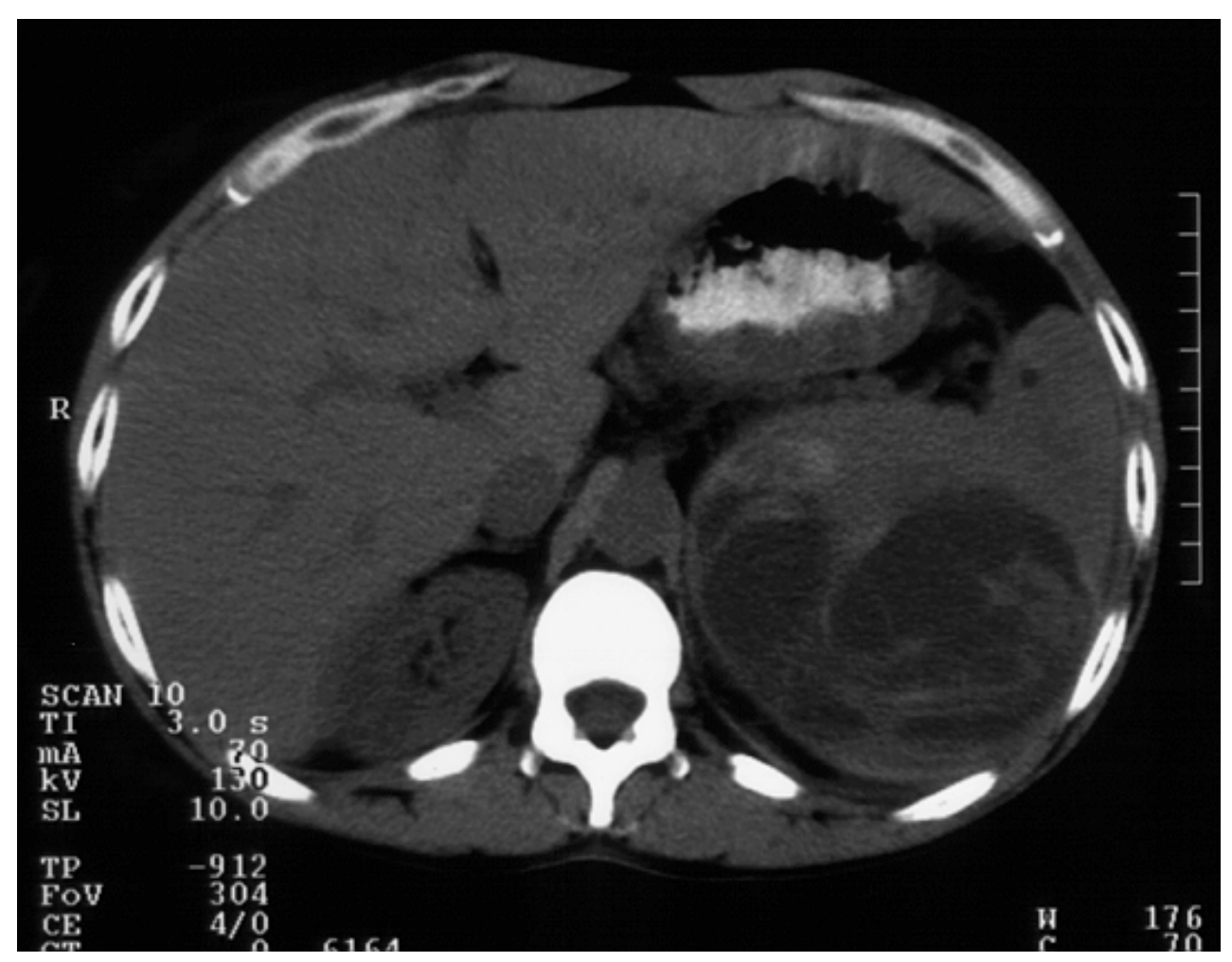

Figura 15 - Extensa coleção perirrenal, não sendo visualizado o rim esquerdo. 


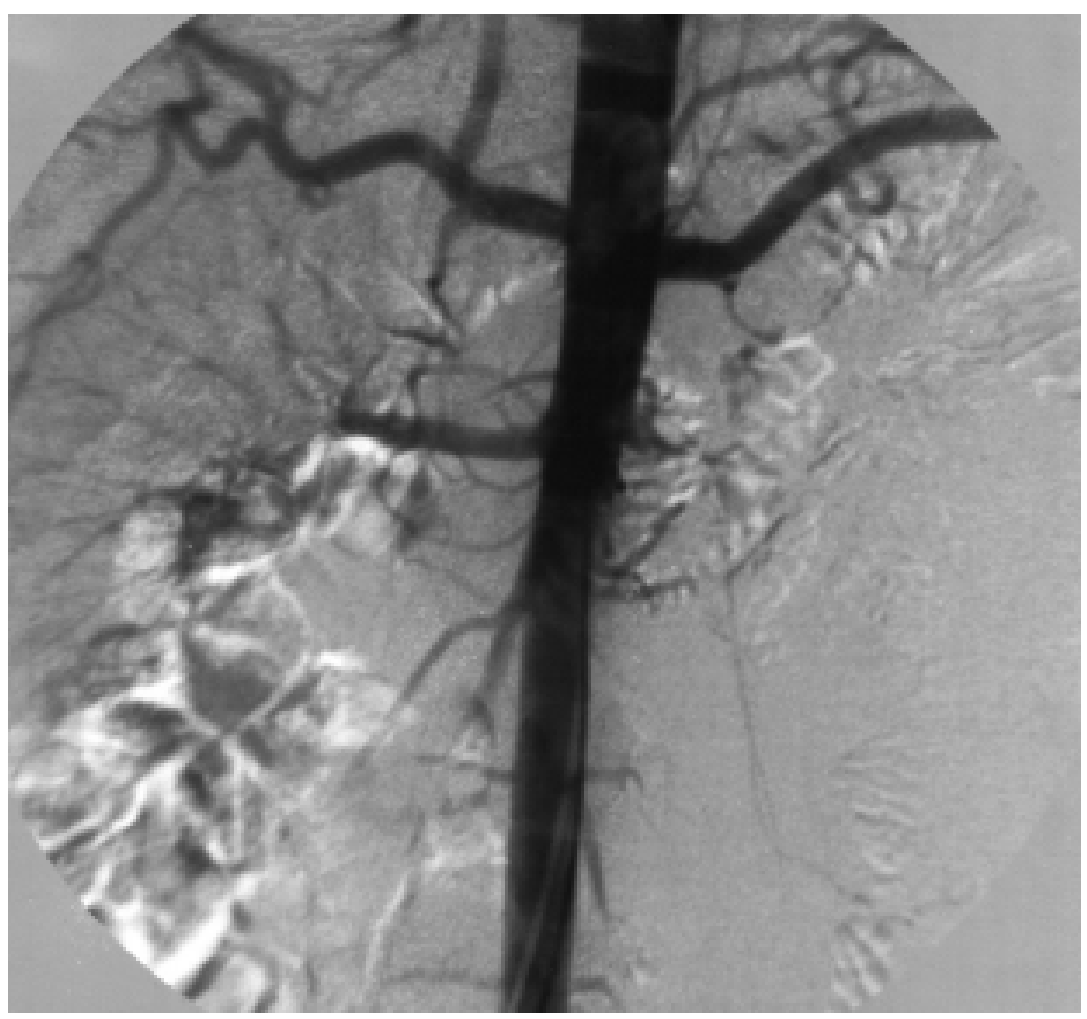

Figura 16 - A arteriografia da lesão apresentada na figura 15, demonstra ausência de contrastação do hilo renal esquerdo. adequadamente a bexiga, verificando-se qualquer extravasamento de contraste. A ultra-sonografia demonstra a presença de material ecogênico no interior da bexiga (coágulos), bem como líquido livre intraperitonial ou coletado no espaço extraperitonial (Figura 17). O extravasamento de contraste intraperitonial coleta-se nos recessos pélvicos, goteiras parietocólicas, espaço entre alças intestinais, e, quando em topografia extraperitonial, o contraste extravazado localiza-se ao redor da base vesical, parede abdominal anterior (espaço de Retzius), escroto, períneo e área perirretal, não sofrendo alteração com a mudança de decúbito do paciente (Figura 18). Eventualmente, pode-se associar à tomografia computadorizada a qual poderá auxiliar na avaliação de pequenos extravasamentos ${ }^{(1,10,11)}$.
Tabela V - Classificação tomográfica do trauma renal

- Grau 1 - Discreta contusão renal, laceração superficial, pequenos hematomas subcapsulares ou perinefréticos.

- Grau 2 - Laceração mais profunda, estendendose para o sistema coletor com extravasamento limitado de urina extra-renal ou hematoma perinefrético, de moderada a grande dimensão.

- $\quad$ Grau 3 - Fragmentação renal, comprometimento da vasculatura, grande extravasamento de urina e grande hematoma rapidamente progressivo.

- Grau 4 - Avulsão ou ruptura da pelve renal ou ureter com o rim intacto.

\section{TRAUMA VESICAL}

A maioria das lesões de bexiga são de localização extraperitonial, freqüentemente relacionadas a fratura da pelve. O exame radiológico de escolha é a uretrocistografia injetora, devendo-se distender-se

\section{TRAUMA PANCREÁTICO}

É raro como lesão isolada, sendo, geralmente, diagnosticado na laparotomia ou em exames de controle. A taxa de falsos negativos é elevada. Os achados tomográficos compreendem laceração, edema focal ou difuso, hemorragia intra ou peripancreática, líquido retroperitonial, espessamento da fascia renal, edema peripancreático e edema envolvendo o mesocólon transverso ${ }^{(9,10,11)}$. A Tabela VI descreve a classificação tomográfica do trauma pancreático ${ }^{(1)}$.

\section{TRAUMA DE VÍSCERA OCA}

Comparativamente às lesões de outros órgãos, nos traumas abdominais fechados, as lesões das vísceras ocas apresentam uma menor incidência relativa, sendo mais freqüentes no intestino delgado, seguindo-se no intestino grosso e estômago.

As lacerações do intestino delgado apresentamse como peritonite, nas horas subseqüentes ao trauma, sendo os locais mais comuns o ângulo de Treitz e a válvula íleo-cecal, enquanto, no duodeno, comprometem-se a segunda e terceira porções. A falta de 
especificidade e a demora no surgimento dos sinais, ao exame físico, dificultam o diagnóstico da lesão intestinal. A demora no diagnóstico e na correção da lesão intestinal aumenta a mortalidade de 05 para $65 \%{ }^{(9)}$. $\mathrm{O}$ cólon transverso é o segmento mais atingido no intestino grosso, podendo as lesões serem do tipo contusão, laceração ou transecção.

A radiologia convencional mostra pneumo ou retropneumoperitônio (Figuras 19 e 20), líquido abdominal, escoliose ou apagamento do contorno do músculo psoas, presentes em menos de $50 \%$ dos casos $^{(24)}$. Os hematomas intramurais são detectados como espessamento difuso da prega ou como massas hiperdensas (60 a $80 \mathrm{UH}$ ) que provocam redução do calibre ou obstrução do lúmen $^{(1)}$.

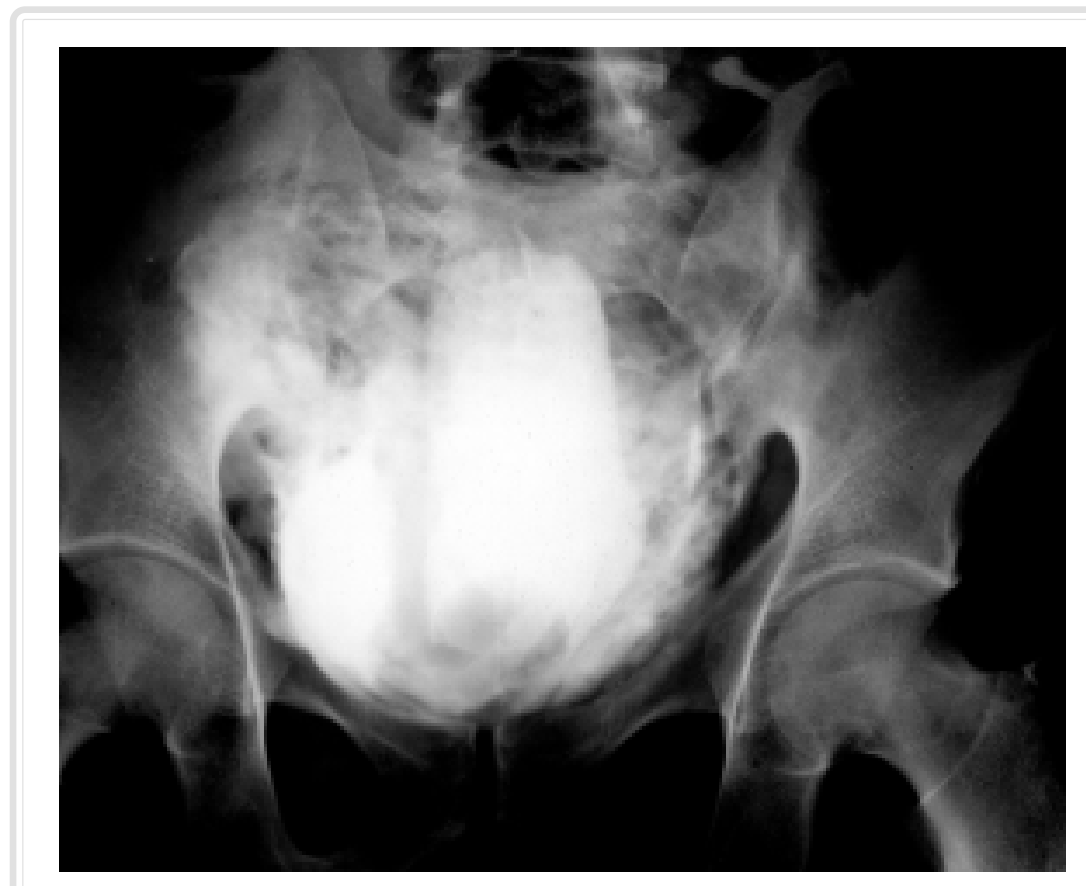

$\overline{\text { Figura } 17 \text { - Rotura vesical com extravasamento de contraste, mostrada pela }}$ uretrocistografia.

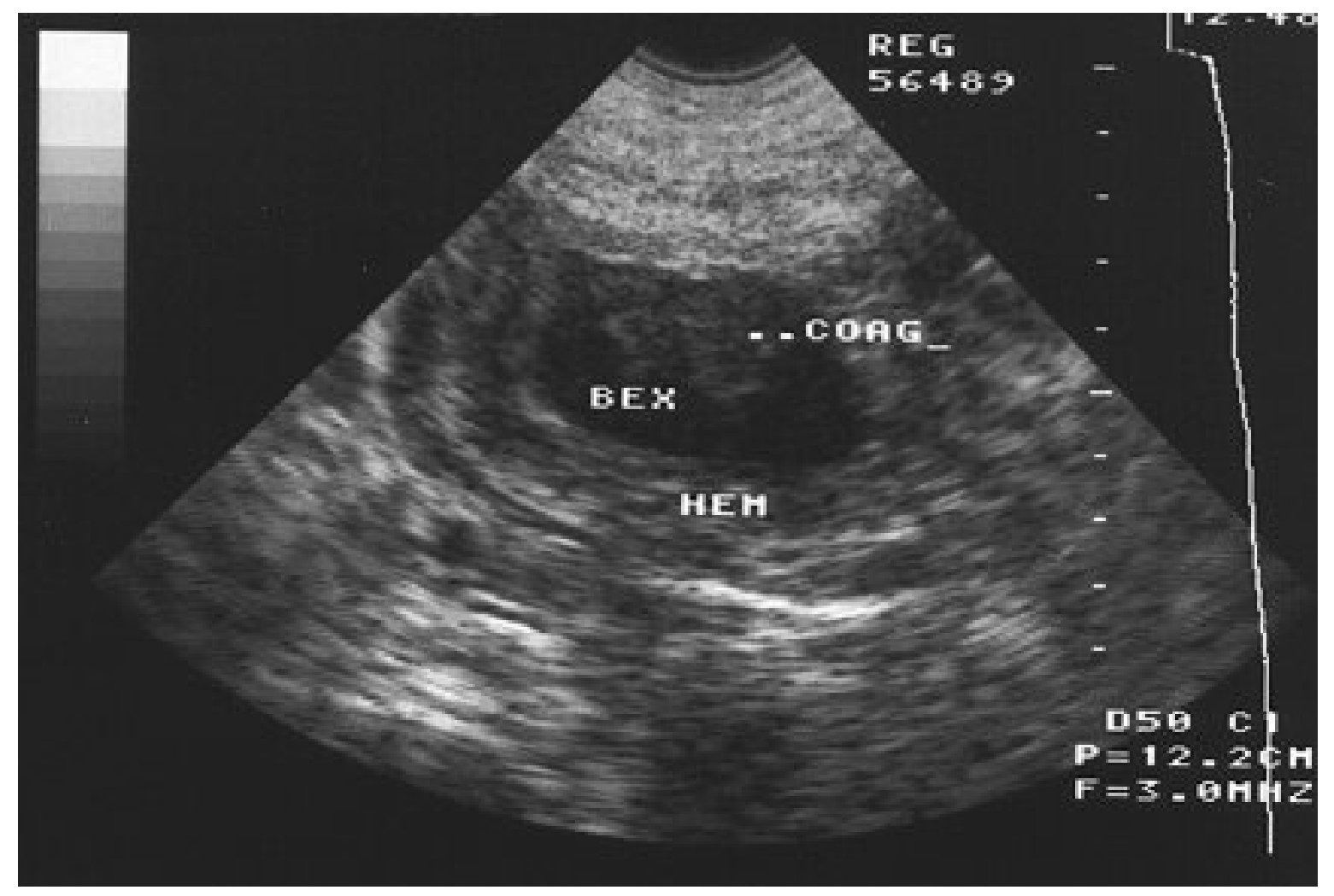

Figura 18 - Ultra-som apresentando rotura vesical com demonstração de hematoma perivesical. 
Tabela VI - Classificação tomográfica do trauma pancreático

- Grau 1 - contusão, laceração com ducto intacto.

- Grau 2 - laceração severa ou transecção do corpo e cauda com provável lesão do ducto pancreático.

- Grau 3 - transecção, hematoma, lesão da cabeça pancreática e do ducto.

- Grau 4 - grau 3 associado a ruptura duodenal

O trauma fechado raramente causa lesão gástrica em função da sua mobilidade, podendo ocorrer laceração da mucosa ou perfuração transmural, apresentando-se como hematoma intramural , extra-serosa ou extravasamento de contraste oral ou $\mathrm{ar}^{(1)}$.

Os principais achados diagnósticos do trauma de víscera oca, na tomografia computadorizada, estão sumarizados na Tabela VII.

\section{TRAUMA DIAFRAGMÁTICO}

Ocorre mais freqüentemente em traumas fechados, variando entre 3 e $5 \%$ dos traumas abdomi-

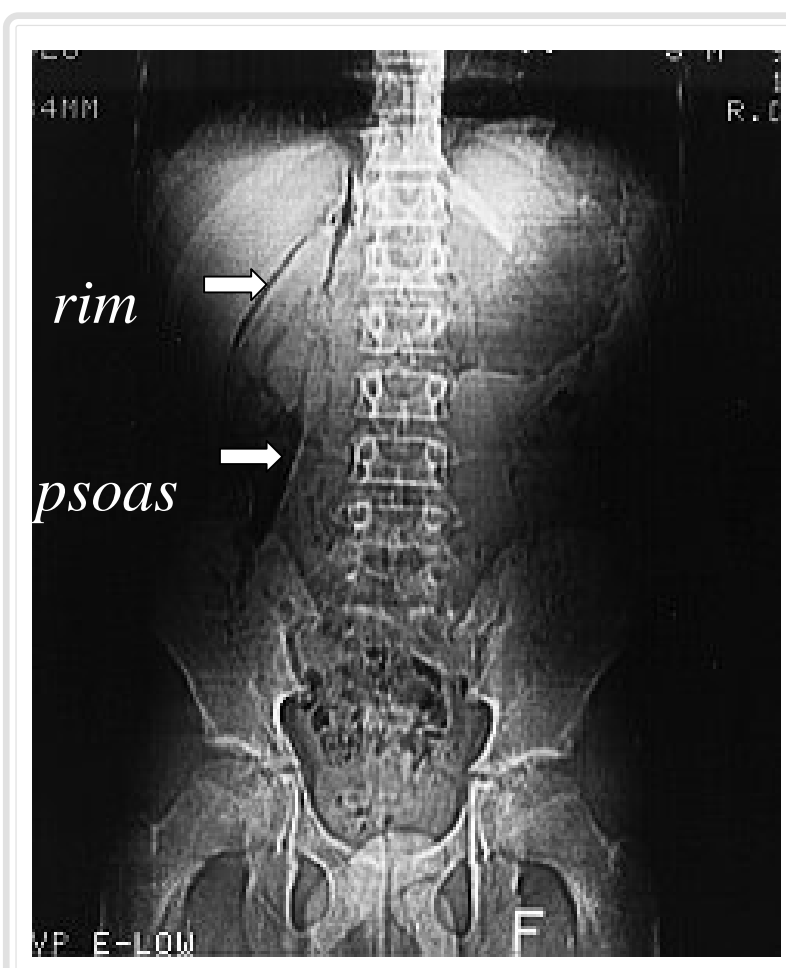

Figura 19 - Retropneumoperitônio pós trauma, visto em radiografia simples do abdome.Observe as linhas hipertransparentes, delineando as estruturas retroperitoniais (setas).

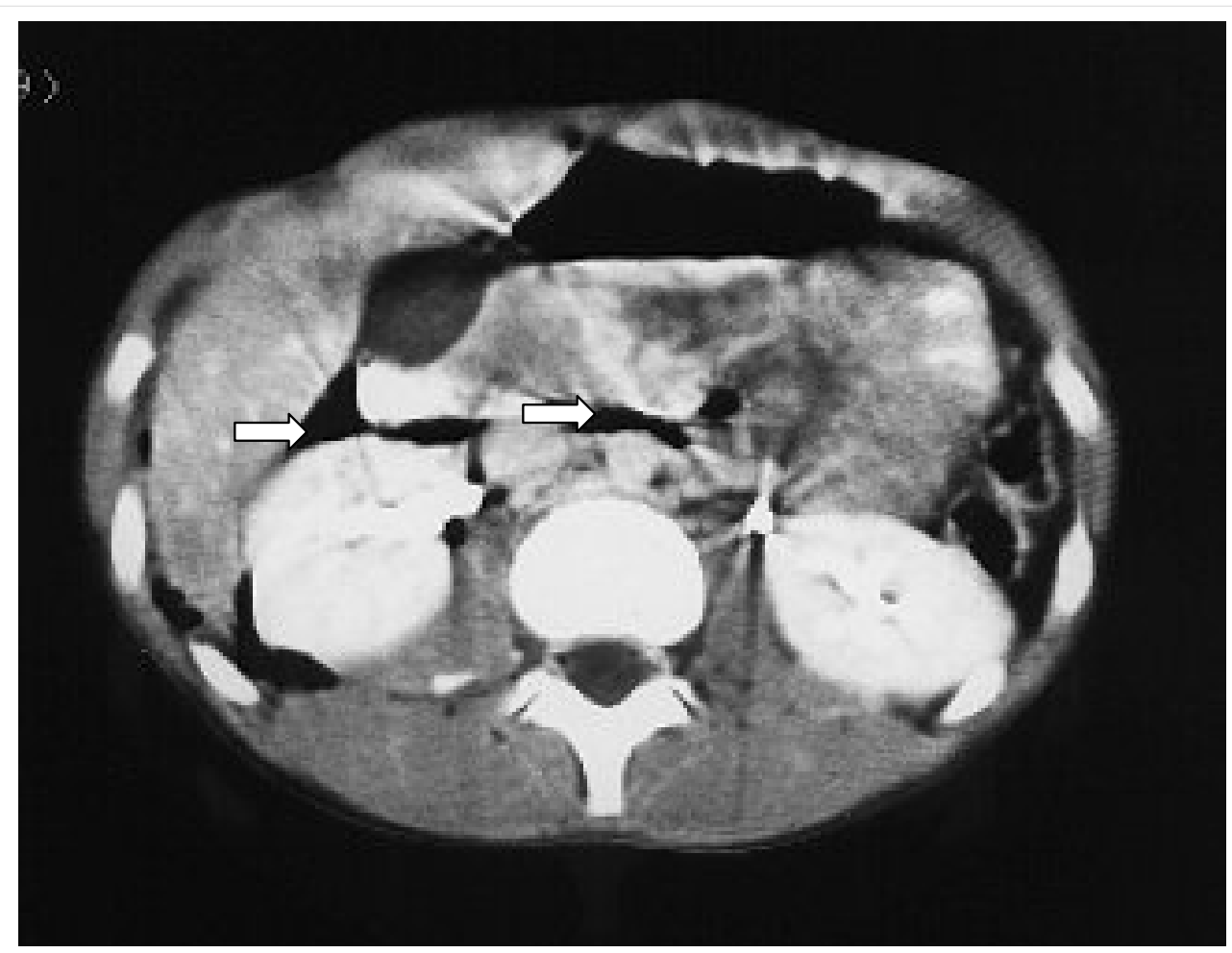

Figura 20 - Retropneumoperitônio evidenciado pela tomografia computadorizada (setas), delineando região pararrenal anterior. 
Tabela VII. Sinais tomográficos de lesão intestinal traumática

- Hematoma mesentérico ou intestinal ${ }^{\#}$.

- Líquido livre intraperitonial sem causa visceral conhecida" .

- Pneumoperitônio e/ou retroperitônio* .

- Líquido retroperitonial não hemorrágico de origem desconhecida* .

- Espessamento da parede intestinal $>3 \mathrm{~mm}$.

- Padrão obstrutivo agudo.

- Interrupção do lúmen com ou sem extravasamento de contraste.

\# indicadores sensíveis, porém inespecíficos.

* indicadores pouco sensíveis, mas específicos.

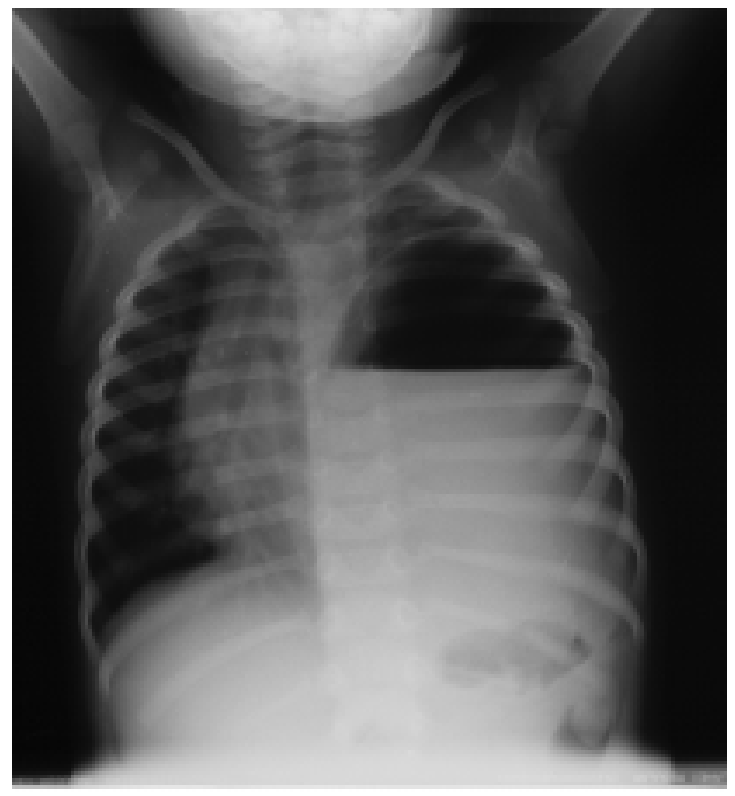

Figura 21 - Rx do tórax em AP. Grande opacidade com nível líquido ocupando o hemitórax esquerdo. nais que necessitam de laparotomia e 0,8 a $1,6 \%$ dos traumas torácicos importantes, com predomínio do lado esquerdo. Os achados radiológicos podem estar ausentes em até $50 \%$ dos casos na fase inicial e incluem elevação ou irregularidade focal do contorno do diafragma, ar ou massa acima do diafragma aparente (Figuras 21 e 22), desvio do mediastino contra-lateralmente, derrame pleural ou atelectasia. Deve-se prestar atenção às patologias que interferem no diagnóstico da ruptura diafragmática, como atelectasia, derrame pleural, contusão pulmonar, paralisia do nervo frênico, derrame subpulmonar, hérnia paraesofágica. A tomografia computadorizada pode visualizar gordura ou víscera abdominal póstero-lateralmente ao diafragma e confirmar defeito do seu contorno, sendo úteis as imagens em reconstrução coronal e sagital ${ }^{(1,25)}$.

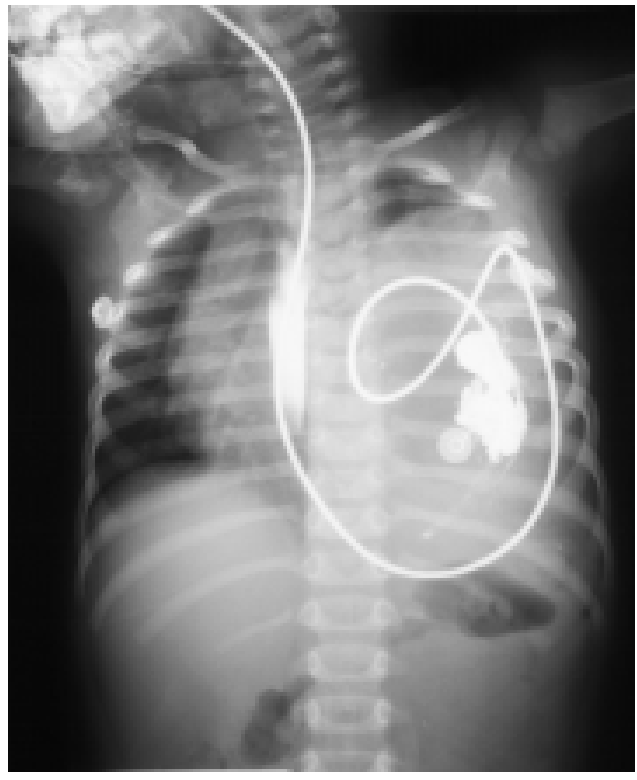

Figura 22 - Rx do tórax em AP. A injeção de contraste por sonda nasogástrica demonstra que, na opacidade, trata-se do estômago herniado através de laceração do diafragma.

LUCCHESIFR; LAGUNA CB; MONTEIROCR; PRADO CHMA \& ELIAS Jr J. Imaging in abdominal trauma. Medicina, Ribeirão Preto, 32: 401-418, oct./dec. 1999.

ABSTRACT: In this update review, we describe recents improvements of diagnostic imaging and their role in practical assistance of abdominal trauma. We also analyze abdominal injury as well as its main radiological features.

UNITERMS: Abdominal Injuries. Diagnostic Imaging. Radiology. 


\section{REFERÊNCIAS BIBLIOGRÁFICAS}

1 - ROBERTS JL. CT of Abdominal and pelvic trauma. Semin Ultrasound CT MR 17: 142-169, 1996.

2 - FELICIANO DV. Diagnostic modalities in abdominal trauma. Surg Clin North Am 71: 241-256, 1991.

3 - GRÜESSNER R; MENTGES B; DÜBER Ch; RÜCKERT K \& ROTHMUND M. Sonography versus peritoneal lavage in blunt abdominal trauma. J Trauma 29: 242-244, 1989.

4 - NORDENHALZ KE; RUBIN MA; GULARTE GG \& LIANG HK. Ultrasound in the evaluation and managment of blunt abdominal trauma . Ann Emerg Med 29: 357-366, 1997.

5 - NOVELLINE RA: Abdomen: Traumatic emergencies. In: HARRIS JR JH.; HARRIS WH \& NOVELLINE RA, eds. The radiology of emergency medicine, 3th ed. Williams and Wilkins, Baltimore, Chapter 9, p. 623-692,1993.

6 - HEALEY MA; SIMONS RK; WINCHELL RJ; GOSINK BB; CASOLA G; STEELE JT; POTENZA BM \& HOYT DB. A prospective evaluation of abdominal ultrasound in blunt trauma: Is it useful? J trauma 40: 875-882, 1996.

7 - BOULANGER BR; McLELLAN BA; BRENNEMAN FD; WHERRETT L; RIZOLI SB; CULHANE J \& HAMILTON $P$. Emergent abdominal sonography as a screening test in a new diagnostic algorithm for blunt trauma. J Trauma 40: 867-874, 1996.

8 - YOSHI H; SATO M; YAMAMOTO S; MOTEGI M; OKUSAWA S; KITANO M; NAGASHIMAA; DOI M; TAKUMA K; KATO K \& AIKAWA N. Usefulness and limitations of ultrasonography in the initial evaluation of blunt trauma. $\mathbf{J}$ Trauma 45 : $45-51$, 1998.

9 - WOLFMAN NT; BECHTOLD RE; SCHARLING ES \& MEREDITH JW. Blunt upper abdominal trauma: evaluation by CT. AJR Am J Roentgenol 158: 493-501, 1992.

10 - RAPTOPOULOS V. Abdominal trauma: Emphasis on computed tomography. Radiol Clin North Am 32: 969-987, 1994.

11 - MIRVIS SE \& SHANMUGANATHAN K. Abdominal computed tomography in blunt trauma. Semin Roentgenol 27: 150183, 1992.

12 - KELLY J; RAPTOPOULOS V; DAVIDOFF A; WAITE R \& NORTON P. The value of non-contrast-enhanced $C T$ in blunt abdominal trauma. AJR Am J Roentgenol 152: 41-46, 1989.
13 - FEDERLE MP \& JEFFREY JR RB. Hemoperitoneum studied by computed tomography. Radiology 148: 187-192, 1983.

14 - MCKENNEY KL. Role of ultrasound in the diagnosis of intraabdominal catastrophes. RadioGraphics 19: 13321339; 1999.

15 - MIRVIS SE; WHITLEY NO; VAINWRIGHT JR. Blunt hepatic trauma in adults: CT-based classification and correlation with prognosis and treatment. Radiology 171: 27-32, 1989

16 - MOORE EE; SHACKFORD SR \& PACHTER HL. Organ injury scaling - spleen, liver and kidney. J Trauma 29: 1664-1666, 1989

17 - MOORE EE; COGBILL TH \& JURKOVICH MD. Organ injury scaling: spleen and liver (1994 revision). J Trauma 38: 323-324, 1995

18 - MCGAHAN JP \& GOLDBERG BB. Diagnostic ultrasound: A logical approach. Lippincott-Raven, Japan, 1998.

19 - WITHERS CE \& WILSON SR. The liver. In: RUMACK CM; WILSON SR \& CHARBONEAU JW, eds. Diagnostic ultrasound, 2 nd ed, Mosby, St. Louis, p. 137-139,1998.

20 - MATHIESON JR \& COOPERBERG PL. The spleen. In: RUMACK CM; WILSON SR \& CHARBONEAU JW, eds. Diagnostic ultrasound , 2 nd ed, Mosby, St. Louis, p.167-170, 1998.

21 - MIRVIS SE; WHITLEY NO \& GENS DR. Blunt splenic trauma in adults: CT-based classification and correlation with prognosis and treatment. Radiology 171: 33-39, 1989

22 - THURSTON W \& WILSON SR. The urinary tract. In: RUMACK CM; WILSON SR \& CHARBONEAU JW, eds. Diagnostic ultrasound, 2 nd ed, Mosby, St. Louis, p. 378-379, 1998.

23 - MIRVIS SE. Diagnostic imaging of the urinary system following blunt trauma. Clin Imaging 13: 269-280, 1989.

24 - RIZZO MJ; FEDERLE MP \& GRIFFITHS BG. Bowel and mesenteric injury following blunt abdominal trauma: Evaluation with CT. Radiology 173: 143-148, 1989.

25 - MIRVIS SE \& TEMPLETON P. Imaging in acute thoracic trauma. Semin Roentgenol 27: 184-210, 1992.

Recebido para publicação em 08/12/1999

Aprovado para publicação em 19/01/2000 


\section{ANEXO I}

\section{Escala de Lesão de Órgãos da Associação Americana de Cirurgia do Trauma}

\section{ESPLÊNICA}

- Grau 1 - Hematoma: subcapsular, área de superfície $<10 \%$

Laceração: ruptura capsular com profundidade no parênquima $<1 \mathrm{~cm}$

- Grau 2 - Hematoma : subcapsular, área de superfície entre 10 e $50 \%$, diâmetro $<5 \mathrm{~cm}$

Laceração : profundidade do parênquima entre $1-3 \mathrm{~cm}$, sem envolvimento de vasos parenquimatosos

- Grau 3 - Hematoma : subcapsular, área de superfície $>50 \%$ ou progressivo. Hematoma intraparenquimatoso $>5 \mathrm{~cm}$.

Laceração: Profundidade $>3 \mathrm{~cm}$ ou envolvendo vasos

- Grau 4 - Laceração de vasos hilares ou segmentares com desvascularização $>25 \%$ do baço

- Grau 5 - fratura esplênica, lesão vascular hilar

\section{RENAL}

- Grau 1 - Contusão : hematúria com exames urológicos normais

Hematoma: subcapsular, não expansivo sem laceraçào do parênquima

- Grau 2 - Hematoma : perirrenal não expansivo, limitado ao retroperitônio

Laceração: profundidade no parênquima $<1 \mathrm{~cm}$, sem extravasamento de urina

- Grau 3 - Laceração : profundidade no parênquima $>1 \mathrm{~cm}$, sem extravasamento de urina
- Grau 4 - Laceração: estendendo -se pela córtex renal, medula e sistema coletor. Lesão da artéria ou veia renal com hemorragia contida

- Grau 5 - laceração: fratura renal, avulsão do hilo renal com desvascularização do órgão

\section{HEPÁTICA}

- Grau 1 - Hematoma : subcapsular, área de superfície $<10 \%$

Laceração: ruptura capsular, profundidade no parênquima $<1 \mathrm{~cm}$

- Grau 2 - Hematoma : subcapsular, área de superfície parenquimatosa entre 10 e $50 \%$, diâmetro $<10$ $\mathrm{cm}$

Laceração: profundidade no parênquima de $1 \mathrm{a} 3 \mathrm{~cm}$, comprimento $<10 \mathrm{~cm}$

- Grau 3 - Hematoma : subcapsular, área de superfície $>50 \%$ ou expansivo.

Hematoma parenquimatoso ou subcapsular roto. Hematoma intra parenquimatoso $>10 \mathrm{~cm}$ ou expansivo

Laceração : profundidade $>3 \mathrm{~cm}$

- Grau 4 - Laceração : ruptura do parênquima envolvendo 25 a $75 \%$ do lobo hepático ou um a três segmentos de Coinaud no mesmo lobo

- Grau 5 - Laceração: ruptura do parênquima envolvendo $>75 \%$ ou $>3$ segmentos de Coinaud no mesmo lobo. Lesão das veias hepáticas ou da veia cava inferior

- Grau 6 - Avulsão hepática 